Portland State University

PDXScholar

Winter 2-26-2015

\title{
A Corpus Based Analysis of Noun Modification in Empirical Research Articles in Applied Linguistics
}

Jo-Anne Hutter

Portland State University

Follow this and additional works at: https://pdxscholar.library.pdx.edu/open_access_etds

Part of the Higher Education Commons, Rhetoric and Composition Commons, and the Technical and Professional Writing Commons

Let us know how access to this document benefits you.

\section{Recommended Citation}

Hutter, Jo-Anne, "A Corpus Based Analysis of Noun Modification in Empirical Research Articles in Applied Linguistics" (2015). Dissertations and Theses. Paper 2211.

https://doi.org/10.15760/etd.2208

This Thesis is brought to you for free and open access. It has been accepted for inclusion in Dissertations and Theses by an authorized administrator of PDXScholar. Please contact us if we can make this document more accessible: pdxscholar@pdx.edu. 
A Corpus Based Analysis of Noun Modification

in Empirical Research Articles in Applied Linguistics

\author{
by \\ Jo-Anne Hutter
}

A thesis submitted in partial fulfillment of the requirements for the degree of

Master of Arts
in
Teaching English to Speakers of Other Languages

Thesis Committee:

Susan Conrad, Chair

Tetyana Sydorenko

Monika Mulder

Portland State University

2015 
C 2015 Jo-Anne Hutter 


\begin{abstract}
Previous research has established the importance of the nouns and noun modification in academic writing because of their commonness and complexity. However, little is known about how noun modification varies across the rhetorical sections of research articles. Such a perspective is important because it reflects the interplay between communicative function and linguistic form.

This study used a corpus of empirical research articles from the fields of applied linguistics and language teaching to explore the connection between article sections (Introduction, Methods, Results, Discussion; IMRD) and six types of noun modification: relative clauses, ing-clause postmodifiers, ed-clause postmodifiers, prepositional postmodifiers, premodifying nouns, and attributive adjectives. First, the frequency of these six types of noun modification was compared across IMRD sections. Second, the study also used a hand coded analysis of the structure and structural patterns of a sample of noun phrases through IMRD sections.

The results of the analyses showed that noun modification is not uniform across IMRD sections. Significant differences were found in the rates of use for attributive adjectives, premodifying nouns, and prepositional phrase postmodifiers. There were no significant differences between sections for relative clauses, ing-clause postmodifiers, or edclause postmodifiers. The differences between sections for attributive adjectives, premodifying nouns, and prepositional phrases illustrate the way the functions of these structures intersects with the functions of IMRD sections. For example, Methods sections describe research methods, which often have premodifying nouns (corpus analysis, conversation
\end{abstract}


analysis, speech sample, etc.); this function of Methods sections results in a higher use of premodifying nouns compared to other sections. Results for structures of noun phrase across IMRD sections showed that the common noun modification patterns, such as premodifying noun only or attributive adjective with prepositional phrase postmodifier, were mostly consistent across sections. Noun phrase structures including pre-/post- or no modification did have differences across sections, with Introduction sections the most frequently modified and Methods sections the least frequently modified. The different functions of IMRD sections call for different rates of usage for noun modification, and the results reflected this.

The results of this research benefit teachers of graduate students of applied linguistics in students' research reading and writing by describing the use of noun modification in the sections of empirical research articles and aiding teachers in the design of materials to clarify the use of noun modification in these IMRD sections. 


\section{Table of Contents}

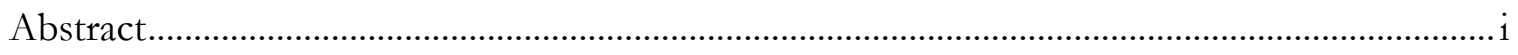

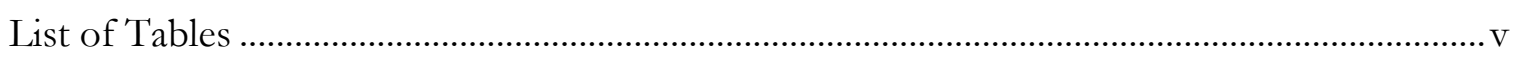

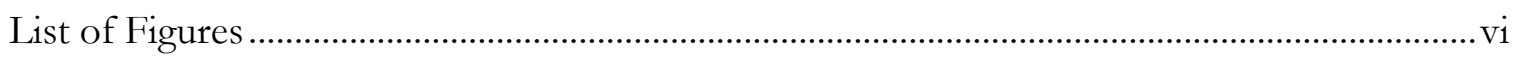

List of Examples................................................................................................................... vii

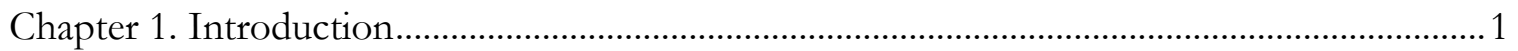

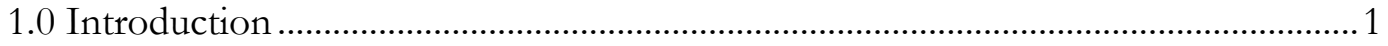

1.1 The Connection between Noun Phrases and Graduate Students ............................ 1

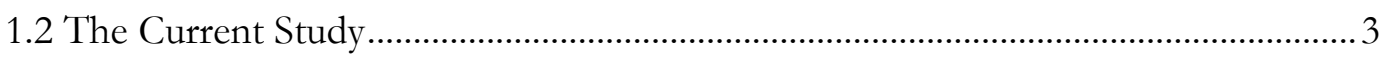

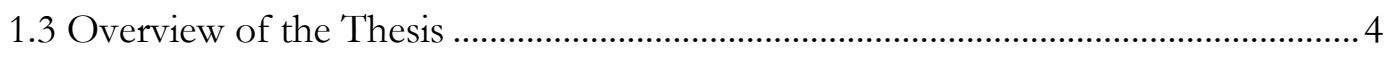

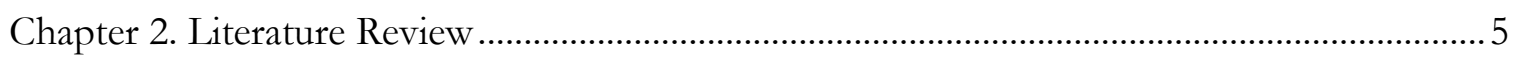

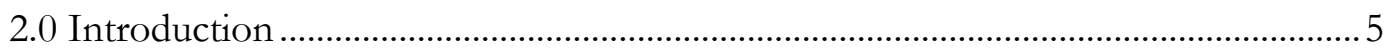

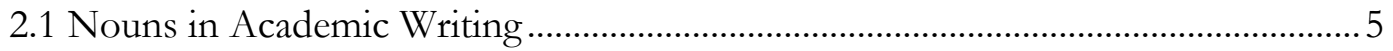

2.1.1 The Importance of Nouns in Academic Writing........................................ 5

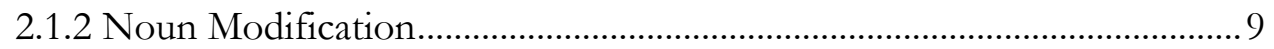

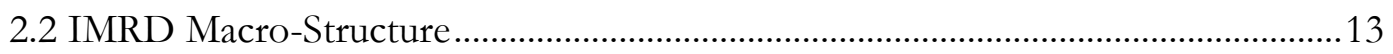

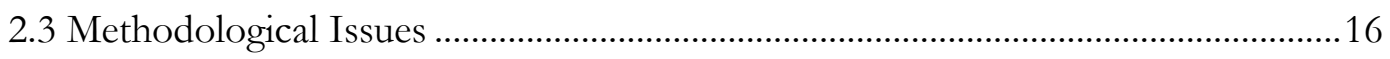

2.3.1 A Register Perspective Using Corpus Linguistics....................................16

2.3.2 Text Types: Distinguishing Genre and Register ......................................19

2.3.3 Considering Genre in Register Analysis....................................................20

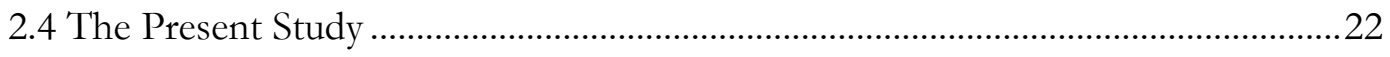

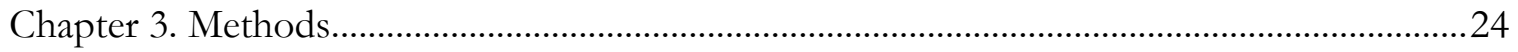

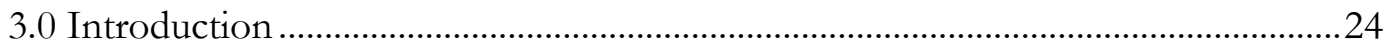

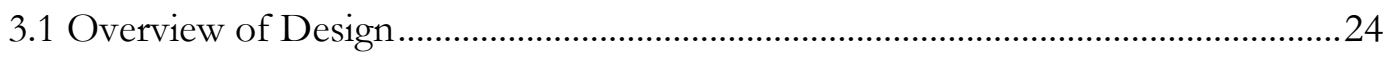

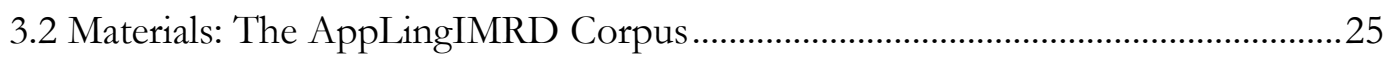

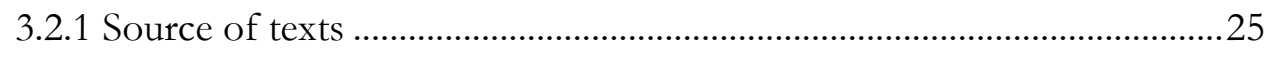

3.2.2 Corpus Organization and Identification of IMRD Sections...................27

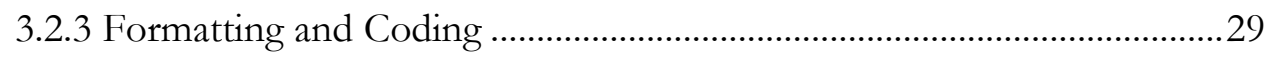

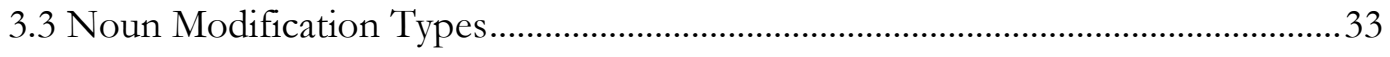

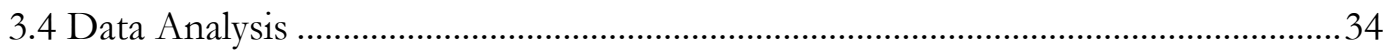

3.4.1 Analysis 1: Comparison of Noun Modification Types ............................34

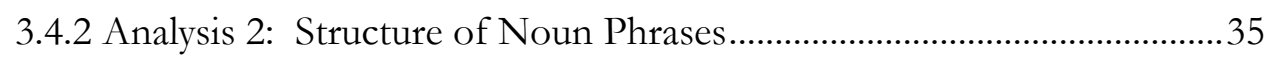




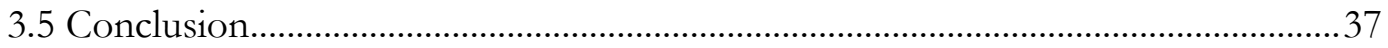

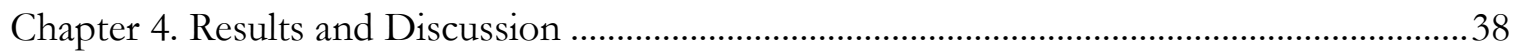

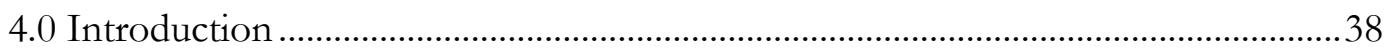

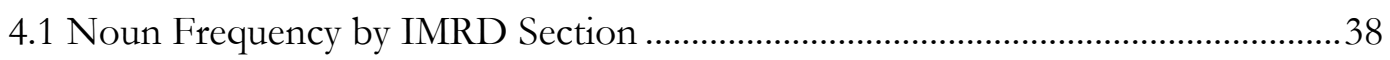

4.2 Analysis 1: Noun Modification Frequency by IMRD Section...................................39

4.2.1 Results of Kruskal-Wallis and Post Hoc Tests ..........................................40

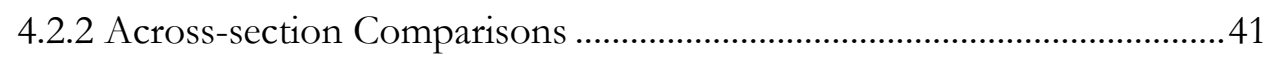

4.3 Analysis 2: Noun Modification and the Structure of Complex Noun Phrases..... 53

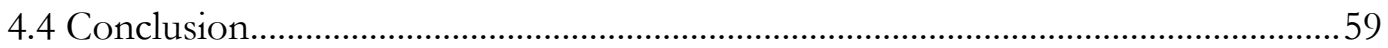

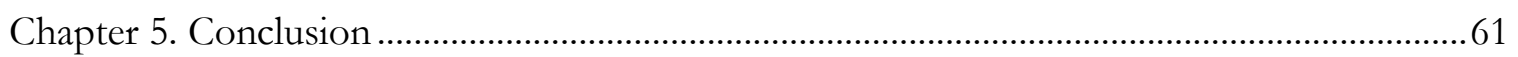

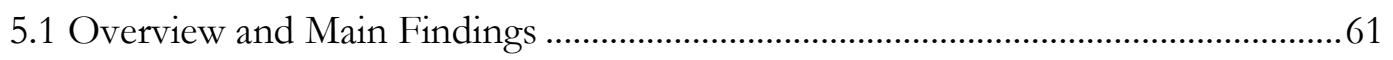

5.1.1 Research Question 1: Frequency Variations of Noun Modification by

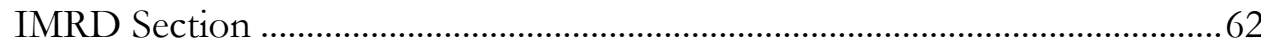

5.1.2 Research Question 2: Complex Noun Phrase Structure and Patterns of

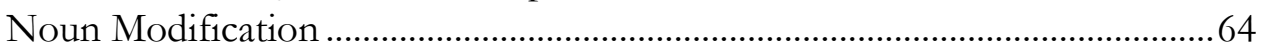

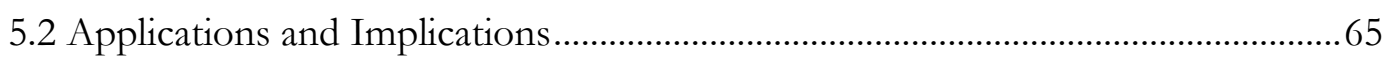

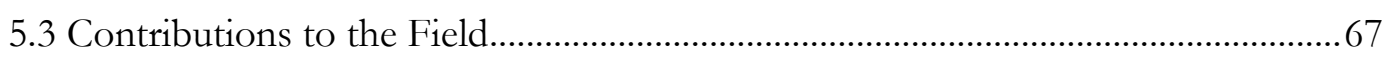

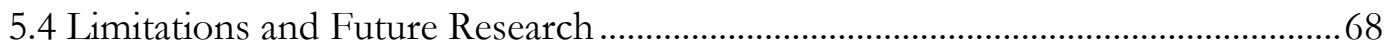

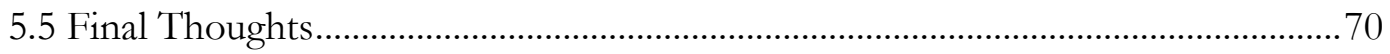

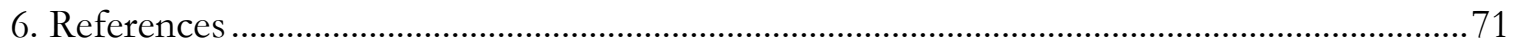

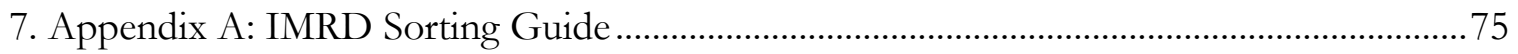

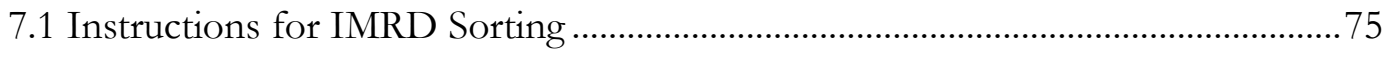

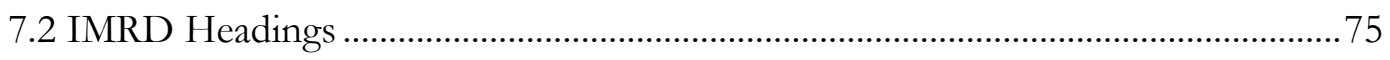

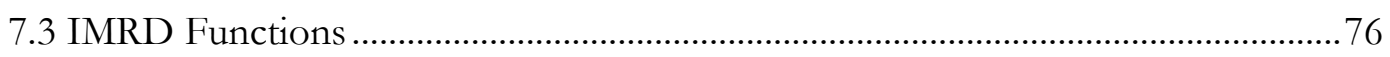

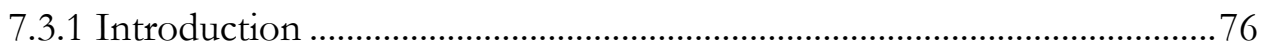

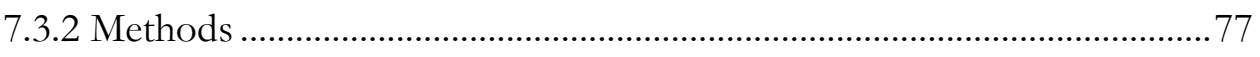

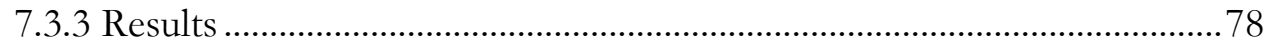

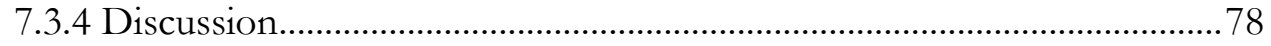

8. Appendix B: Human Subjects Review Not Required........................................................... 80 


\section{List of Tables}

Table 3-1. Overview of journals included in the corpus...................................................26

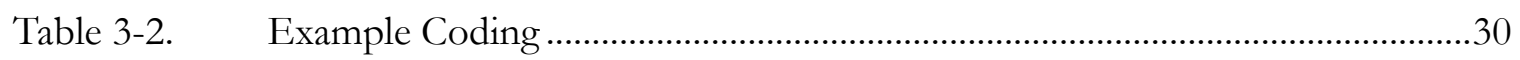

Table 3-3. Types of Noun Modification Investigated .........................................................34

Table 4-1. Nouns per 1000 words in the AppLingIMRD Corpus......................................38

Table 4-2. Kruskal-Wallis Results for Comparisons of Noun Modification Types

between IMRD Sections .............................................................................. 40

Table 4-3. Pairwise Mann-Whitney U Comparisons across Sections, Attributive

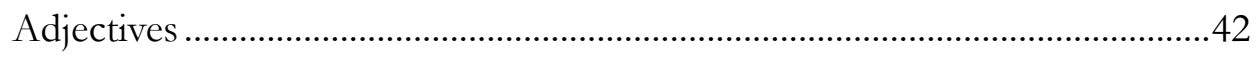

Table 4-4. Pairwise Mann-Whitney U Comparisons across Sections,

Noun Premodifers

Table 4-5. Pairwise Mann-Whitney U Comparisons across Sections, Prepositional

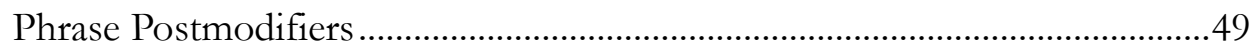

Table 4-6. Noun phrase structures in Analysis 2 ...........................................................55

Table 4-7. Common Patterns of Noun Modification by Section ......................................58

Table 5-1. High/Low Use of Significant Noun Modification Types by Section.............63 


\section{List of Figures}

Figure 2-1. Conrad's continua of corpus linguistics research (2015), with marks

for the current study .18

Figure 4-1. Means across sections for attributive adjectives, normed by 1000 nouns........41

Figure 4-2. Means across sections for noun premodifiers, normed by 1000 nouns...........45

Figure 4-3. Means across sections for prepositional phrases, normed by 1000 nouns ......48

Figure 4-4. Means across sections for relative clauses, normed by 1000 nouns...................52

Figure 4-5. Means across sections for ing-clause postmodifers, normed by 1000 nouns..52

Figure 4-6. Means across sections for ed-clause postmodifers, normed by 1000 nouns ...53

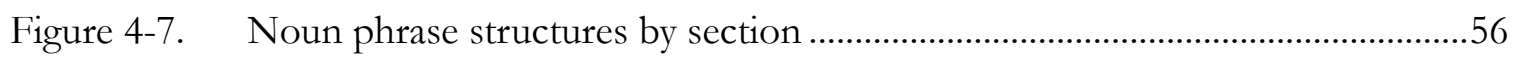

Figure 4-8. Diagram of modified noun phrase "generalizations made in the field of ELF interaction".

Figure 4-9. Diagram of modified noun phrase "Thai language that is spoken mainly in 19 provinces throughout Northeast Thailand, an area of the country that experiences an average $13.05 \%$ poverty rate..." 


\section{List of Examples}

Example 1-1. Relationships between Head Noun and Modifiers...............................................2

Example 2-1 Examples of lexical density in spoken conversation and academic

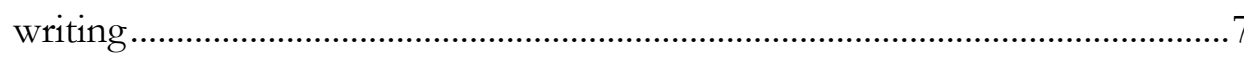

Example 2-2. First element of sentence bolded ……….........................................................

Example 2-3. First element of sentence bolded ................................................................

Example 2-4. Noun Modification Stacking in a Noun Phrase from a Research Article......10

Example 2-5. Compressed and Elaborated Structures............................................................12

Example 3-1. Functional Results Section with Content-Specific Heading ............................28

Example 3-2. Exploratory triangulation techniques that combine screen recordings, stimulated recalls, and corpus-query analysis to examine the behaviors and development of L2 writers in their interactions with the corpus ............36

Example 4-1. Examples of attributive adjective use by IMRD section, with attributive adjectives bolded

Example 4-2. Examples of noun premodifier use by IMRD section, with noun premodifiers bolded .47

Example 4-3. Examples of the length of prepositional phrase postmodifiers. .50 


\section{Chapter 1. Introduction}

\subsection{Introduction}

In several years as a tutor of graduate students learning English for entry to university study, I have noticed that my students often struggle with adjusting to reading and producing research writing. Much is this difficulty is because of the language of research writing, especially the use of nouns. As Halliday points out, "a pile-up of nouns ... is hard to understand both for [English L1 and L2] ... students of science” (1993, p. 69). Noun phrases, especially complicated noun phrases, are difficult, and academic writing abounds with them (Biber, Johansson, Leech, Conrad, \& Finegan, 1999). For my students, complex noun phrases were troublesome, and I saw them grapple with the relationships of noun phrases' complex parts and the many ways to modify nouns.

\subsection{The Connection between Noun Phrases and Graduate Students}

Graduate students, whether English is their L1 or L2, face the task of learning the linguistic norms of their community. One of these norms is the grammatical features, especially noun phrases and noun modification. As "junior members" of their research communities (Swales \& Feak, 2004, p. 42), graduate students must learn how to handle complex noun phrases (Parkinson and Musgrave, 2014, p. 48). Likewise, graduate students in

many fields are expected to become effective consumers and producers of research writing, which as part of academic writing is nominally complex text type (Biber \& Gray, 2010; Biber, Johansson, Leech, Conrad, and Finegan, 1999). More specifically, in my program of study, the MA TESOL program at Portland State University, every student must produce 
research writing, either through a thesis or an empirical writing class that accompanies a project or comprehensive exam. The road to these culminating experiences is paved with coursework with required reading of published research. Thus, for students to be socialized into the language community of research writing through coursework and research, descriptions of research writing as a text type are vital.

This task of language socialization includes learning the appropriate use of grammatical features of the text type of research writing. Previous research on research writing has shown the importance of the grammatical feature of complex noun phrases (Biber, Johansson, Leech, Conrad, \& Finegan, 1999, and described further in the literature review). Complex noun phrases include a noun and some sort of noun modification. These structures can be confusing for students, as I have observed in my experience tutoring English L2 students. See Example 1-1, an illustration of the complex relationships between a head noun and the structure or structures that modify it (which may themselves be modified).

\section{Example 1-1}

Relationships between Head Noun and Modifiers

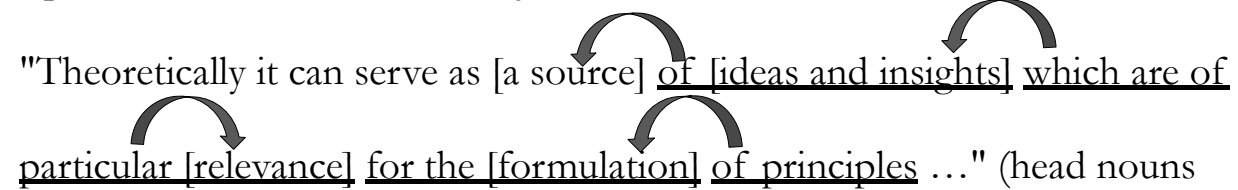

bracketed, each instance of noun modification underlined separately)

(Biber et al., 1999, p. 640)

Immediately we can see that this noun phrase is complicated. While the top head noun source has only one prepositional phrase modifier, the object of that preposition is 
itself modified by a relative clause that contains yet more modification. Between the highest level source and the lowest level of principles, there are four instances of noun modification stacked on top of each other. It is no wonder that students unfamiliar with a register heavily laden with noun modification might have difficulty unpacking the structures. Because of noun modification's commonness and difficulty in academic writing, investigations that aim to describe the text type would do well to consider this distinctive trait of academic writing.

However, in addition to characterizing research writing (and its nouns) as a whole, we must also consider the macro-structure of research articles. Empirical research articles compose a relatively rigid genre (Biber \& Conrad, 2009) and follow an expected structure, delineated by separate sections that represent the various functions that the article must accomplish, such as providing a credible support for the research in the Introduction section or describing research procedures in the Methods section. This format of Introduction, Methods, Results, Discussion (IMRD) is the default reference point for empirical research articles, and an understanding of this format is necessary to be able to effectively navigate a research article. Additionally, these functional differences between sections (described further in the literature review) are likely to correspond to a difference in the use of grammatical features and therefore noun modification across sections. This is because of the widely accepted concept in linguistics that there is a relationship between linguistic form and communicative function (Biber et al., 1999, pp. 14, 41-4).

\subsection{The Current Study}

While previous research has described the characteristics of broad types of texts, such as academic writing (Biber \& Gray, 2010; Liu, 2008; Biber, Conrad, Reppen, Byrd, \& Helt, 
2002) and research articles (Conrad, 1999; Hyland, 2008; Wei \& Lei, 2011), less often studied are comparisons of the sections of research articles in terms of their grammatical differences. In order to describe the use of noun modification in research articles, it is helpful to investigate this text type while considering the role of macro-structure and sections. This study will investigate the use of noun modification in four text categories within empirical research articles in applied linguistics and language education: Introduction, Methods, Results, and Discussion sections. It will compare the frequencies of several noun modification types by section and the patterns of complex noun phrases containing noun modification.

\subsection{Overview of the Thesis}

Chapter 2 gives an overview of the literature relevant to this study, including a discussion of noun modification in academic writing, the macro-structure of research articles, and issues that informed the study's methodological choices. Chapter 3 outlines the methods for this corpus-based register analysis and how they will answer the research questions posed at the end of the literature review. Chapter 4 presents the results and discussion, while Chapter 5 interprets these in the conclusion, with discussion of applications and implications, contribution to the field, and areas for future study. 


\section{Chapter 2. Literature Review}

\subsection{Introduction}

This chapter covers the relevant research for the current study. First I discuss noun phrases and noun modification, as well as their importance. Following this, I explore the organizational structure of research articles, namely Introduction Methods Results Discussion (IMRD) to illustrate their functions within the research article. I then discuss methodological issues for the study, including text types, register, genre, and an argument that a nuanced study of research articles requires a finely grained register analysis informed by rhetorical structure.

\subsection{Nouns in Academic Writing}

Nouns and noun modification are important in academic writing generally and research writing more specifically. Not only are nouns themselves more common in academic writing but they also more commonly feature noun modification (Biber et al., 1999) and compressed phrasal structures (Biber \& Gray, 2010) compared to other text types, such as spoken conversation. The following sections outline the features and importance of nouns in academic writing, including noun modification, types of noun modification, and justifications of why nouns are so important for this text type.

\subsubsection{The Importance of Nouns in Academic Writing}

Nouns and complex noun phrases are important in academic writing. This is due to three reasons: their prevalence, their challenge to learners, and their power in texts. First, consider the use of nouns and noun phrases in academic writing compared to other 
registers. Nouns are much more common in academic writing than in registers like spoken conversation and fiction writing (almost 300 thousand nouns per million words in academic writing versus about 150 thousand nouns and 225 thousand nouns per million words in conversation and fiction respectively, according to Biber et al., 1999, p. 65). In addition to being more common, nouns in academic writing also more often feature noun modification, which lengthens the noun phrases and increases their grammatical complexity compared to unmodified noun phrases. Noun modification is rare in spoken conversation with only $15 \%$ of nouns having some sort of modification, but it is very common in academic writing with the majority of nouns having modification (60\%, Biber et al., 1999, p. 578).

Next, nouns in academic writing are not only common (and commonly modified) compared to other registers, but they are also challenging for both L1 and L2 students. This is largely because of the grammar of science writing (Halliday, 1993, p. 71). Halliday's description of the reasons for science writing's difficulty gives several reasons. Out of these, two are especially relevant for our discussion of noun modification: syntactic ambiguity and lexical density. Syntactic ambiguity is the lack of clarity that arises when grammatical relationships are not explicit. It is difficult to interpret a noun phrase when those relationships are ambiguous. For example, in the noun phrase pressure hose, there is nothing to mark the relationship between hose and pressure. Is this a hose for increasing or decreasing pressure, or a hose that has pressure? Lexical density is the high count of lexical words compared to function words in a phrase or clause. Academic writing and research articles can have very high lexical density, especially in contrast with spoken conversation. Compare these two examples (Example 2-1), one from spoken conversation (cited in Halliday, 1993, p. 76) and the other from a research article in applied linguistics (Saiegh-Haddad, Hadieh, \& 
Ravid, 2012). We can see the marked difference in lexical density in this example. Lexical density, which allows for informationally dense texts, an advantage in condensed research article writing, also makes the language harder to understand. Notice that the increase in lexical density in the example comes from nouns or noun modifiers (adjectives and past participles).

\section{Example 2-1}

Examples of lexical density in spoken conversation and academic writing

\begin{tabular}{|l|l|l|}
\hline $\begin{array}{l}\text { Spoken } \\
\text { conversation }\end{array}$ & $\begin{array}{l}\text { But we never did anything very much in } \\
\text { science at our school }\end{array}$ & $\begin{array}{l}\text { 3 lexical words } \\
/ 12 \text { words }\end{array}$ \\
\hline $\begin{array}{l}\text { Academic } \\
\text { writing }\end{array}$ & $\begin{array}{l}\text { the similar developmental trajectories } \\
\text { revealed in the two productions tasks for } \\
\text { SFP and BP morphological structures }\end{array}$ & $\begin{array}{l}\text { / } 16 \text { lexical words } \\
\text { SPords }\end{array}$ \\
\hline
\end{tabular}

The next consideration of the importance of nouns and noun phrases in academic writing is their power. As Cullip (2000) argues in his discussion of grammatical metaphor and nominalization, nouns are tools with many strengths. Noun phrases have elasticity; they "can be stretched syntactically and packed semantically" (p. 85) in ways that other phrases, such as verb phrases, cannot. For example, in the noun phrase the absence of an authority to monitor the movement of ships carrying waste (p. 85), the phrase has been structurally stretched with numerous modifiers (e.g., prepositional phrase postmodifiers, to-clause postmodifier, and ing-clause postmodifier), which also pack more and more meaning into the head noun absence.

Noun phrases also have more power in terms of their positions in the sentence and concomitant rhetorical power. Noun phrases can occupy many different positions and therefore direct the flow of given/new information. In Example 2-2 and 2-3, two versions 
of a sentence from this literature review show the utility of nouns to direct information flow. These two versions of the sentence have the same content; however, in 2-6, it is clear that we are talking about syntactic ambiguity as the known information and the rest of the sentence will tell us about it. In contract, the first noun phrase of 2-7 suggests that an information flow in which we first discuss lack of clarity and then name it, with lack of clarity as known information. This ability to structure for given and new information is important because it allows writers to control the emphasis and impact of the elements in their sentences, as well as to signal important topics in the writing through their positioning. This sort of structuring is more difficult with verbs or other parts of speech (Cullip, 2000, p. 86).

\section{Example 2-2}

First element of sentence bolded

Syntactic ambiguity is the lack of clarity that arises when grammatical relationships are not explicit.

\section{Example 2-3}

First element of sentence bolded

\section{The lack of clarity that arises when grammatical relationships are not} explicit is syntactic ambiguity.

Thus, the ability to manipulate nouns is powerful rhetorically. The role of nouns in information flow "is an extremely important tool for the rhetorical structuring of a text for a particular purpose” (Cullip, 2000; p. 88); positioning noun phrases allows for rhetorical structuring and the manipulation of verbal arguments, which is vital to academic writing. 


\subsubsection{Noun Modification}

Noun phrases in academic writing have greater complexity compared to other registers, due to their high frequency of noun modification (Biber et al, 1999, pp. 574-643). Noun modification describes a head noun (Biber et al., 1999, p. 97) Noun modification consists of premodification (attributive adjectives, noun premodifiers, etc.) and postmodification (relative clauses, appositive noun phrases, prepositional phrase postmodifiers, etc.). Noun modification is especially common in academic writing; according to Biber et al. (1999, p. 578 ), about $60 \%$ of nouns have premodification, postmodification, or both, which makes it much more common compared to other registers, such as conversation or fiction. For example, as mentioned above, only $15 \%$ of noun phrases in conversation have noun modifiers, and fiction writing similarly has noun modification in only approximately $30 \%$ of its noun phrases. Noun modification clearly plays a much larger role in academic writing than in either conversation or fiction; therefore, noun modification can be an important part of a study that aims to characterize a type of academic writing.

Noun phrases in academic writing not only feature noun modification in greater frequency than many other registers, but they also often contain multiple instances of noun modification stacked on the same noun head (Biber et al., 1999, pp. 578-9). At times, these complex noun phrases can become very long. This can be seen in Example 2-4, drawn from an empirical research article (Saiegh-Haddad, Hadieh, \& Ravid, 2012). Inside this noun phrase headed by trajectories, there are three modifiers: two attributive adjectives and a long relative clause postmodifier; inside the relative clause modifiers are two more layers of modifiers. One layer down, tasks is pre- and postmodified by a noun phrase and 
prepositional phrase. This is followed by yet another layer headed by structures with a noun phrase and attributive adjective premodifier.

\section{Example 2-4}

Noun Modification Stacking in a Noun Phrase from a Research Article

Phrase: the similar developmental trajectories revealed in the two productions tasks for SFP and BP morphological structures

\begin{tabular}{|l|l|l|l|}
\hline similar & developmental & trajectories & $\begin{array}{l}\text { revealed in the two } \\
\text { productions tasks for SFP } \\
\text { and BP morphological } \\
\text { structures }\end{array}$ \\
\hline $\begin{array}{l}\text { attributive } \\
\text { adjective }\end{array}$ & $\begin{array}{l}\text { attributive } \\
\text { adjective }\end{array}$ & head noun & $\begin{array}{l}\text { ed-clause postnominal } \\
\text { modifier }\end{array}$ \\
\hline
\end{tabular}

Phrase: two productions tasks for SFP and BP morphological structures

\begin{tabular}{|l|l|l|l|}
\hline & productions & tasks & $\begin{array}{l}\text { for SFP and BP } \\
\text { morphological structures }\end{array}$ \\
\hline (none) & $\begin{array}{l}\text { noun } \\
\text { premodifier }\end{array}$ & head noun & prepositional phrase \\
\hline
\end{tabular}

Phrase: SFP and BP morphological structures

\begin{tabular}{|l|l|l|l|}
\hline SFP and BP & morphological & structures & \\
\hline $\begin{array}{l}\text { noun } \\
\text { premodifier }\end{array}$ & $\begin{array}{l}\text { attributive } \\
\text { adjective }\end{array}$ & head noun & $\begin{array}{l}\text { (no modifier in this } \\
\text { position) }\end{array}$ \\
\hline
\end{tabular}

That noun phrases in academic writing are often long and stacked with noun modification is important for a few reasons. One of these is the connection between function and linguistic form. A characteristic of academic writing is its informational density, which is linked to dense noun phrases (Parkinson \& Musgrave, 2014, p. 49, cf. lexical density in Halliday, 1993, pp. 76-77). The prevalence of noun modification allows more content in noun phrases, leading to a higher density in the text. 
Another reason for the importance of long and stacked noun phrases is novice learners. To a learner, the complex noun phrases found in academic writing can be overwhelming, as I have seen with my students. Learning to understand and produce long noun phrases like the one in Example 2-4 is part of the task of writers who are new to research articles.

\subsubsection{Compressed and Elaborated Structures in Noun Modification}

Another concept important in noun modification is the concept of compressed versus elaborated structure: Biber and Gray (2010) and Biber, Gray, and Poonpon (2011) introduced this concept in studies contrasting the use of these structures in academic writing and conversation. Elaborated structures are clausal; relative clauses, ing-clauses, and edclauses, for example, all contain verbs. They are called "elaborated" because their structure elaborates the grammatical relationship between the head noun and its modifier. Compressed structures are phrasal; compressed structures include attributive adjectives and prepositional phrases, which are phrases and lack verbs (Biber \& Gray, 2010, pp. 9-11). Compressed structures allow content to be condensed into the structure.

Biber and Gray found that these two types of structures have differences in their frequency as well as function. Compressed structures are more common in academic writing than in conversation. In contrast, elaborated structures are more common in spoken conversation. Turning to the functions of academic writing and spoken conversation, we can see the communicative functions that appear to motivate the difference in grammatical expression. Academic writing in general, associated with compressed structures in Biber and Gray's findings, is dense both lexically and informationally (Parkinson \& Musgrave, 2014; 
Halliday, 1993) and planned, often undergoing rounds of editing and revising. In contrast, spoken conversation, associated with elaborated structures, lacks the lexical and informational density of academic writing and is generally unrehearsed.

Consider this in light of the characteristics of elaborated and compressed structures as described in Biber and Gray (2010). Elaborated structures spell out the relationships between the head noun and its modifier, which makes them grammatically explicit. In contrast, compressed structures are dense and pack meaning into modification; their density comes at the expense of explicitness, as the grammatical relationships between head noun and modifier are not spelled out. In Example 2-5 from Biber and Gray (2010, p. 11), we can see the grammatical inexplicitness of noun premodifiers (compressed structure).

\section{Example 2-5}

Compressed and Elaborated Structures

\begin{tabular}{|l|l|}
\hline Compressed structure & Elaborated structure \\
\hline pressure hose & a hose that is able to withstand pressure \\
\hline pressure ratio & a ratio that measures pressure \\
\hline
\end{tabular}

In their study, Biber and Gray compared widely-delineated registers in their study (academic writing and spoken conversation), but they did not look within the parts of texts. However, just as registers have functions, the parts of texts also have their own functions (see descriptions of IMRD functions in Section 2.2.1), so it is useful to consider these two structure types (with their functional differences) in the functionally motivated differences between sections of research articles. The concepts of elaborated and compressed structures add another dimension to considerations of academic writing and noun modification. 
Instead of merely stating that functional differences in IMRD sections are related to frequency differences of noun modification between those sections, compressed and elaborated structures give us an organizational scheme. Now it is possible to investigate whether those noun modification differences are related to the functional differences of compression and elaboration; this adds depth to the investigation. An investigation of compressed and elaborated structures within sections of a text category is important because it helps to demonstrate the grammatical expression of the sections' functions.

\subsection{IMRD Macro-Structure}

For understanding text types, including the text type of empirical research articles, we can turn to genre analysis. Genre analysis is defined by Biber and Conrad (2009) as analyzing the text as a whole, including its macro-structure and rhetorical sections. While a text as a whole has a function (that is, empirical research articles describe primary research for their scientific community), the rhetorical sections that compose the macro-structure have functions as well. For research articles, this macro-structure is Introduction, Methods, Results, and Discussion (IMRD), and its functions are described in detail below.

Research articles in many fields have been studied from the perspective of structural organization, and their macro-structure has been well documented. The macro-structure of research articles (RAs) is the IMRD format, which is commonly accepted as standard in both research writing guides and studies of empirical research articles. It consists of Introduction, Methods, Results, and Discussion. These sections are defined and described by their features and functions in a variety of sources (Swales, 1990; Day \& Gastel, 2011; and Cargill and O'Connor, 2009). Introduction sections build the background and justification 
for the study (Swales, 1990, pp. 137-148). Methods sections give procedural information to demonstrate the credibility of the study and allow for future replication of the study (Cargill \& O'Connor, 2009, pp. 35-36). Results sections display the results of the study (Swales, 2009, pp. 170-171). Discussion sections draw Introductions and Results together by "show[ing] the relationships among observed facts" (Day \& Gastel, 2011, p 73). Thus, each of these sections has a function and builds the "IMRAD Story" (Day \& Gastel, 2011; IMRAD as alternate name for IMRD).

This structure is widely known and taught to graduate students, including graduate students in the MA TESOL program where this study took place. This instruction can be seen in sources that analyze RAs and ones that describe them for pedagogical purposes (e.g., writing guides). Works such as Day's How to write and publish scientific articles, which was published originally in 1979 and has run to seven editions, up to 2012 (Day, 1979; Day \& Gastel, 2012) describe how to write IMRD sections. Other works that discuss IMRD format for pedagogical purposes include Swales and Feak (2004), Cargill and O’Connor (2009), and Perry (2011). This format, then, is clearly presented to students as the assumed way to organize scholarly articles.

IMRD structure is also used as a guideline for experienced writers. It is the structure given by the APA Publication Manual as the standard for researchers to follow in their articles for clarity and ease of communication (American Psychological Association, 2010, pp. 21-36). Additionally, scholarly journals commonly refer to IMRD structure in their guidelines for paper submissions. For example, the author guide for the journal English for Specific Purposes states that article structure should include Introduction, Material and Methods, Results, Discussion, and Conclusions sections. Other journals, such as TESOL 
Quarterly or Language Learning, specify that paper submissions should follow APA Guidelines, which specify IMRD format. IMRD structure, then, is pervasive in academic empirical research writing at both the novice and professional level.

However, there are variations in research article structuring. Not all empirical research articles follow the IMRD format, and several researchers have investigated variation in the genre structure of research articles in different disciplines. Lin and Evans (2011) studied the choices researchers make for structural patterns; surveying articles in a wide range of disciplines, they found that while the IMRD format is "still one of the major structural patterns, it is by no means the default option" (p. 153). The most frequent formats found in their study had Introduction, optional Literature Review heading, Methods, combined Results and Discussion, and finally Conclusion. In another study, working more specifically within the discipline of Applied Linguistics, Yang and Allison (2004) used a body of 40 research articles and found that the articles maintained the general macro-structure of IMRD format but that individual headings and organizational choices appeared to motivate structures whose headings lay outside the usual IMRD format, such as Theoretical Basis, Research Focus, Literature Review, as well as headings specific to particular articles. While the two previous studies of IMRD format both found that research articles did not solely use IMRD format, there is nevertheless reason to continue to consider it the dominant general form. Non-IMRD headings, including the ones in the two previous studies, can in general be categorized as one of the IMRD sections, according to function. These non-IMRD headings often "capture the macro-structure" of IMRD format (Yang \& Allison, 2004). For example, Theoretical Basis, Research Focus, and Literature Review all fall under the function of the Introduction section to "create a research space" (Swales, 1990) by 
giving the literature and theoretical background that lead to the research focus and questions. As alternatives to a Discussion heading, Conclusion and Pedagogical Implications both fulfill similar functions to the Discussion, at least in part, by discussing the findings, limitations, and applications or implications and wrapping up the article. Therefore, the substitutes to IMRD headings are generally not functionally different from the verbatim Introduction, Methods, Results, and Discussion headings, and using IMRD macro-structure for work that investigates research articles remains useful.

\subsection{Methodological Issues}

This study used register analysis to investigate noun modification in IMRD sections of research articles. Register analysis is the analysis of a category of text using the features (in this case grammatical) throughout the text (Biber \& Conrad, 2009). The following sections of the literature review discuss the methodological issues of the study, including register analysis with corpus linguistics, analysis of text types using genre and register, and the gap between register and genre.

\subsubsection{A Register Perspective Using Corpus Linguistics}

Register analysis and corpus linguistics commonly go hand in hand. Corpus linguistics is a computer-aided investigation of large bodies of naturally occurring texts gathered for a principled design (Conrad, 1996). Because of corpus linguistics' ability to analyze the pervasive features within or between text types, it is a useful tool for studying text types and the lexicogrammatical features associated with them. 
In order to understand some of the ways register analysis contributes to our understanding of text types, it is helpful to consider a model that categorizes the focus of particular register analyses. Conrad (2015) describes two continua to categorize studies of register that use corpus linguistics (see Figure 2-1). The first involves the lexical, grammatical, and lexicogrammatical features that are analyzed; the continuum ranges from separate features to multidimensional analysis of constellations of features that occur together. The second continuum varies based on the register used in the study; the continuum runs through individual registers, multiple registers, sub-registers, and discourse units as parts of a single register. Consider the two following examples and the way they use register analysis to describe text types.

The first example is Conrad's 1996 study, which used multidimensional analysis to investigate differences between two registers within academic writing, ecology textbooks and ecology research articles. Her study found that for the dimension of impersonal/nonimpersonal style, ecology textbooks were less impersonal than ecology research papers, using fewer past participial clauses and passives; these findings have implications for ecology students who have experience reading general academic writing and ecology textbooks but who need to learn to write ecology research. This study also exposed differences between the two seemingly close text types investigated, even though both would have fallen under a more general academic writing umbrella in wider register analyses; the narrow definition of register contributed to the field of register analysis by finding differences that a wider definition of register would not have found.

Another example is Cortes' (2013) study of lexical bundles within one sub-register, research article introductions. Cortes' study investigated a group of lexical features (lexical 
bundles) in a sub-register (Introduction section of research articles); her study found that certain lexical bundles occurred in particular places inside Introduction sections, which increased the understanding of research articles and their characteristics, beyond the previous rhetorical model of Introduction sections (Swales, 1990). In other word, the linguistic features inside one section of one register varied and were not uniform through the subregister; the differences in linguistic form were related to the functions of Introduction sections.

\section{Figure 2-1}

Conrad's continua of corpus linguistics research (2015), with marks for the current study

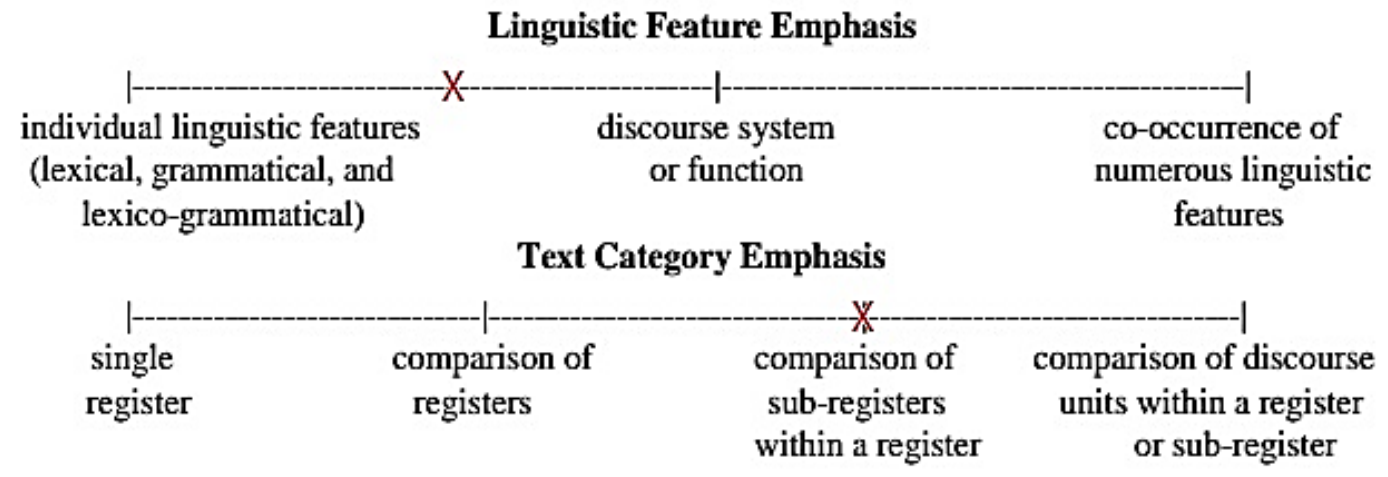

Within the framework of these two continua, the current study uses six grammatical features and a comparison of sub-registers within the register of empirical research writing, as shown in Figure 2-1, with marks for the current study. 


\subsubsection{Text Types: Distinguishing Genre and Register}

Following Biber and Conrad (2009) definitions, I consider genre analysis and register analysis as two means of investigating text types with different approaches: genre analysis looks at the sections and moves of a text as a whole, while register analysis concerns itself with the linguistic features. This section distinguishes the two approaches and then explains why both are important for the present study.

Genre analysis, described by Swales (1990) as well as Biber and Conrad (2009), is concerned with the characteristics of texts as a whole through formatting, sequential organization, and rhetorical functions. Headings and sections are relevant to genre analysis because it seeks to describe texts types as a whole. Rhetorical functions are identified by analyzing purposes and micro-purposes within sections, as in Introduction sections in research articles that have the function of setting the stage and establishing the need for the study (Swales, 1990). These rhetorical moves of a text together are the macro-structure of that text as a whole. Rare but indexical language features, such as once upon a time at the beginning of fairytales or but wait there's more in the sales pitch of television infomercials), are important because they point to a particular genre, but the analysis of vocabulary and grammar choices is not the primary focus of the approach.

In contrast, register analysis is concerned with features that are distributed throughout a text; register investigations focus on pervasive linguistic features everywhere in the text, as opposed to ones in particular places in a text, as in genre analysis. These features can be lexical, grammatical, or lexico-grammatical; even groups of features may be the subject of analysis. For example, Biber and Gray's (2010) study of differences between spoken conversation and academic writing used groups of grammatical features such as 
relative clauses, appositive phrase postmodifiers, and adverbial clauses to characterize the differences between those two registers. Another example is Wahid's (2013) study of definite article the usage across three registers over several varieties of English worldwide; he compared the usage by type (such as idiomatic or generic usage) between private conversation, academic writing and news.

Both a register perspective and a genre perspective have contributed to our knowledge of the characteristics of text types. My study will use both of these: the IMRD sections of research articles (genre) as a basis for an analysis of noun modification (register). By bringing these two perspectives together in a register analysis of the sections of a text type, it is possible to investigate grammatical differences in the sections within one category. With a starting point of the sections of a text type, sourced from a genre perspective, a register analysis of that text type will be better able to consider functions within the text type and how they result in linguistic differences between sections. The present study uses IMRD sections as the unit of analysis for a register analysis.

\subsubsection{Considering Genre in Register Analysis}

While it is possible to characterize academic writing generally, as in the research discussed in 2.3.1, other studies have shown that even within one academic written register, linguistic features are not uniform through parts of a text. Investigating grammatical features between IMRD sections, Biber and Conrad (2009) described verb tense differences in those sections, such as greater use of present tense in Introductions and greater use of past tense in Methods. Introductions and Methods perform different functions. Introductions build arguments and make generalizations about a field, which is accomplished by a mix of 
present and past tense, while Methods describe completed procedures, which requires past tense. Swales' (1990) description of IMRD sections included a review of studies that compared parts of IMRD structure, including nominal that-clauses (higher use in I and D sections than M and R sections; West, 1980) and passive voice (low use in I section, high use in $\mathrm{M}$ sections, and variable use in $\mathrm{R}$ and D sections; Heslot, 1982, as cited in Swales, 1990). These studies have helped us to gain a richer understanding of the sections of a register previously seen as monolithic. While other research approaches research articles as a single text type or part of a larger register of academic writing, these studies illuminated linguistic differences within research articles.

Other studies have also used methodology that investigated the interplay between features and IMRD sections. Durrant and Matthews-Aydınl, (2011) used a "function-first" approach to identify rhetorical moves in academic essays and scholarly articles, followed by analysis to determine the sentence structures used to realize those moves. Another study of linguistic features with generic moves or sections was conducted by Cortes (2013); it investigated lexical bundles in Introductions of research articles, which were then analyzed for function and grammatical structure. These studies add to the knowledge of research articles by using the space between genre analysis and register analysis; they both illustrate the non-homogeneity of research articles.

Given these studies, it appears likely that the four IMRD sections co-occur with variation in grammatical features, including noun modification. Each section of a research article serves a function that works to build the text as a whole, and different functions are tied to differences in linguistic form. Making the distinction between these sections allows a 
finer analysis and consequent illumination of grammatical features that vary with those functions, namely noun modification in the present study.

\subsection{The Present Study}

Given the interplay between form and function, it stands to reason that the communicative functions that motivate those differences may also be reflected in different sections.

Previous research, however, has not frequently used generic sections in a register analysis of academic texts, despite the value of a narrowly defined register. While some studies have investigated formulaic language in the generic moves of research articles and graduate student essays, and others have investigated features such as tense and personal pronouns in sections in research articles, no articles that I am aware of have conducted register analysis of noun modification between sections of research articles. We have seen in the research described above that both IMRD sections and compressed and elaborated structures have functional differences, and I expected to find noun modification differences sorted by compressed/elaborated structures, such as more elaboration in IM and more compression in RD.

The purpose of the present study was to explore differences in noun modification between sections of research articles in Applied Linguistics. Specifically, I answered the following research questions:

RQ1 How do the frequencies of noun modification features vary between the IMRD sections of research articles in Applied Linguistics? How do the differences of 
compressed and elaborated structures by section illustrate the functions of IMRD sections?

RQ2 What are the structures of complex noun phrases in the IMRD sections of these articles? What are the common noun modification patterns in these complex noun phrases? How do these structures shed light on the noun modification frequencies found in RQ1? 


\section{Chapter 3. Methods}

\subsection{Introduction}

This chapter describes the methods of the current study exploring noun modification use in the four IMRD sections. First I give an explanation of the overall design. This is followed by a description of the corpus used in the study. Finally, I describe the data analysis methods used to answer the two research questions.

\subsection{Overview of Design}

This study used a corpus-based approach to investigate noun modification in the sections of empirical research articles in order to explore the intersection of genre and register by using IMRD sections with an analysis of several grammatical structures. The corpus used for the analyses was one that I compiled for the study to reflect the specific register under investigation, namely IMRD sections in empirical research articles in the field of TESOL/language education. This corpus-based study used two analyses of a grammatically tagged corpus of research articles to illustrate the differences in six types of noun modification between IMRD sections. The two analyses each contributed a different view of noun modification use in IMRD sections. Analysis 1 aimed to identify frequency differences between IMRD sections of six noun modification types. Analysis 2 probed into the structure of noun modification in IMRD sections and identified common noun modification patterns to understand the structure and use of noun modification beyond frequency by section. 


\subsection{Materials: The AppLingIMRD Corpus}

The materials consist of the AppLingIMRD corpus, which I compiled specifically for the study. I compiled the corpus for the study because no available corpora met the specifications of the study. The study's 220,000-word corpus was composed of a total of 30 articles from 5 journals in the field of applied linguistics. The relatively small size of the corpus reflects the genre analysis that I used to identify the IMRD sections of each article, which required reading through the articles. The size of the corpus satisfied issues of practicality while still being large enough for statistical analysis.

\subsubsection{Source of texts}

The corpus consists of empirical research articles of peer-reviewed scholarly journals in the field of applied linguistics and language education. I selected articles from Applied Linguistics, Language Learning, TESOL Quarterly, Modern Language Journal, and English for Specific Purposes. I chose the journals as examples of recent, high quality, and typical journals that are used in MA TESOL programs that I had been exposed to as a graduate student of my MA TESOL program. Additionally, these journals were diverse in their focus within applied linguistics/language education. One of these focused on English education, such as TESOL Quarterly, while another focused on education in other languages (Modern Language Journal). Some approached the field in a general way, as in Applied Linguistics, while others used a narrower view within language education, such as English for Specific Purposes.

To confirm that these journals were high quality scholarly journals, I used two further selection criteria: age of publication and $\mathrm{H}$ index. I chose age as one criterion because older journals are well established in the field. Because of their long publication 
history, these journals have a stable track record and have had time to build credibility, in contrast to new journals with only a handful of issues. I used $\mathrm{H}$-index to ensure the journals have a substantial impact on the field. H-index is a measure of the citations a journal or author receives; more specifically, the number reflects the number of articles that have $\mathrm{H}$ number of citations; for example, if a journal has 25 articles that have at least 25 citations, the journal's H-index is 25 . This index of journal impact "[c]ombines publication activity and citation influence" (Öchsner, 2013, pp. 51-54). Journals with a higher H-index (more citations in more articles) represent a model of empirical research articles in the field of applied linguistics and language education because they impact the field through a high number of highly cited articles. The five journals, the length of their publication history, and their $\mathrm{H}$ index are listed in Table 3-1.

\section{Table 3-1}

Overview of journals included in the corpus

\begin{tabular}{|l|l|l|}
\hline Journal & $\begin{array}{l}\text { Age / Years of } \\
\text { Publication }\end{array}$ & H factor \\
\hline Applied Linguistics & $\begin{array}{l}33 \\
1980-2013\end{array}$ & 41 \\
\hline Language Learning & 65 & 40 \\
& $1948-2013$ & \\
\hline TESOL Quarterly & 32 & 39 \\
& $1981-2013$ & \\
\hline Modern Language Journal & 97 & 28 \\
& $1916-2013$ & \\
\hline $\begin{array}{l}\text { English for Specific } \\
\text { Purposes }\end{array}$ & $\begin{array}{l}29 \\
1980-1981,1986-2013\end{array}$ & 27 \\
\hline
\end{tabular}

The five journals all have a publication history greater than 30 years and an $\mathrm{H}$ index greater than 25. These criteria ruled out newer or less-impactful journals that I had 
encountered in my program, such as International Journal of Corpus Linguistics, Journal of English for Academic Purposes, and English Language Teaching Journal.

I selected articles from 2012, the 2012 issue being the most recent complete issue at the time of corpus compilation in 2013. I started with the most recent issue of the 2012 volume for each journal and moved backward chronologically in order to have recent articles. Special editions were excluded, as special editions vary both in article type (in having synthesis or review articles) as well as communicative function.

The articles themselves were selected based on type of article. All of the articles are empirical and contain original research. For the purpose of inclusion, no distinction was made for descriptive, or experimental/quasi-experimental methods, as long as the article was empirical. Several types of articles were excluded due to their function and organizational structure, which differs from that of empirical research articles: meta-analyses, position papers, forum discussions, and book reviews.

\subsubsection{Corpus Organization and Identification of IMRD Sections}

The corpus was divided into four subcorpora, based on the IMRD format. As discussed in the literature review, IMRD structure is the main organizational framework for empirical research articles; moreover, even articles that use alternate heading names generally still fulfill the functions of IMRD format. Because of this, I used IMRD sections as the organizational unit in the corpus. This was accomplished via an IMRD identification guide that I developed based on previous genre research of IMRD sections (Appendix A); the identification guide used headings and section functions to identify the IMRD sections. The procedure for sorting articles into IMRD sections was relatively simple. For unproblematic 
articles, I first used headings and subheadings to assign the IMRD sections. When the headings and subheadings did not clearly indicate which IMRD section to assign, I skimmed the text and used function descriptions based a synthesis of previous research to assign sections as covered in the IMRD identification guide. The majority of the articles (26 of the 30) had obvious IMRD sections labeled or had very clear functional sections. An example of a clear functional section can be seen in Example 3-1. This passage fits the category of Results because it gives the results, in this case the broad overview of the interview. It has a topic-specific heading and an initial sentence that functions to introduce results (note the terms case and illustrate that).

\section{Example 3-1}

Functional Results Section with Content-Specific Heading

Heading: Joonho's Family: Conflicts and Negotiation Between Language Ideologies of the Imagined Community and Personal Desire to be Distinctive The case of Joonho's family, who lived in the United States from 2004 to 2008 with the mother only, illustrates how her perspective shifted over time as she negotiated between the language ideologies of the IC and her personal desire to distance herself from other ESA families.

Four of the articles were more problematic to subdivide. Their headings did not reveal functional sections, and the functions of sections appeared more mixed or lacked the clear lexical signals of function that the unproblematic articles contained. For these articles, I consulted with a colleague in the MA TESOL program who was familiar with genre analysis. 
The purpose of the consultation was not inter-rater reliability, but rather to have two readers trained in genre analysis come to agreement on the identification of sections whose boundaries were unmarked and whose functions were less obvious than the other articles and sections. This colleague used headings and functions to make a judgment of the problematic articles. Finally, the colleague and I discussed the problematic articles to reach a consensus. For one particularly problematic article, my colleague and I were not able to reach a consensus on IMRD boundaries, and we agreed that this article appeared to have a structure that did not orient towards IMRD structure and more closely resembled a narrative. Since the focus of my study is to investigate grammatical variation between IMRD sections, this article did not fit the criteria for inclusion in the study, so I removed it from the corpus and replaced it with another article, which I successfully sorted into IMRD sections.

\subsubsection{Formatting and Coding}

The texts in the corpus were formatted and coded as part of the corpus compilation process. This included substitution and removal of certain parts of texts because of their lack of relevance to IMRD format and the types of noun modification under study. Parts of research articles that were not included were the following: abstract, notes, appendices, tables or figures, and reference lists. These parts of the texts were either omitted (abstract, notes, appendices, and reference lists) or replaced by a text comment, for example $<$ ttable $>$ and $<$ ffigure $>$, for tables and figures.

Quotations in the texts were treated in one of four ways, depending on if they were academic quotations (i.e. quotes from other research articles), blocked text examples, 
examples serving as nominal units in the sentence, or examples incorporated into the sentence. Each of these is illustrated in Table 3-2, showing the text before and after coding. The purpose of this coding was to differentiate between examples that were congruent with the register of this study (that is, academic writing in research articles in applied linguistics/language education) and examples that belonged to a different register that needed to be excluded from the analysis (for example, chat room excerpts or Spanish legal terminology).

Table 3-2

Example Coding

\begin{tabular}{|c|c|c|}
\hline Example type & Example before coding & Example after coding \\
\hline $\begin{array}{l}\text { 1. Academic } \\
\text { quotes } \\
\text { Left in text }\end{array}$ & $\begin{array}{l}\text { Dines's (1980: 22) claim that GEs } \\
\text { share a 'common discourse } \\
\text { function', namely, marking the } \\
\text { element preceding a GE as an } \\
\text { illustrative example of a more } \\
\text { general superset, has formed the } \\
\text { cornerstone of functionally based } \\
\text { definitions of the variable } \\
\text { context adopted in many } \\
\text { previous studies of GEs. }\end{array}$ & $\begin{array}{l}\text { Dines's (1980: 22) claim that GEs } \\
\text { share a 'common discourse } \\
\text { function', namely, marking the } \\
\text { element preceding a GE as an } \\
\text { illustrative example of a more } \\
\text { general superset, has formed the } \\
\text { cornerstone of functionally based } \\
\text { definitions of the variable } \\
\text { context adopted in many } \\
\text { previous studies of GEs. }\end{array}$ \\
\hline $\begin{array}{l}\text { 2. Blocked } \\
\text { quotes } \\
\text { Replaced with } \\
\text { <example>, } \\
\text { not tagged }\end{array}$ & $\begin{array}{l}\text { Each occurrence was interpreted } \\
\text { in context of discourse to ensure } \\
\text { that it expressed disagreement, as } \\
\text { in the use of sorry in examples } \\
\text { (1) and (2): } \\
\text { M4 ehm I'm sorry that I'm } \\
\text { slow with understanding this } \\
\text { but ehm ehm I just haven`t } \\
\text { quite understood the technical } \\
\text { implications of } \\
\text { this ... (CEMS18) } \\
\text { M1 ... so I suggest that we } \\
\text { have eh a system installed }\end{array}$ & $\begin{array}{l}\text { Each occurrence was interpreted } \\
\text { in context of discourse to ensure } \\
\text { that it expressed disagreement, as } \\
\text { in the use of sorry in examples } \\
\text { (1) and (2): } \\
\text { <eexample> }\end{array}$ \\
\hline
\end{tabular}




\begin{tabular}{|c|c|c|}
\hline & $\begin{array}{l}\text { which will monitor the e-mails } \\
\text { (and) the employees but that } \\
\text { the employees might like } \\
\text { themselves or not feel too } \\
\text { abused about }\end{array}$ & \\
\hline \multirow{4}{*}{$\begin{array}{l}\text { 3. Phrase / } \\
\text { clause } \\
\text { serving as a } \\
\text { single unit in } \\
\text { a sentence } \\
\text { Replaced with } \\
\text { eexample, } \\
\text { tagged as a } \\
\text { noun }\end{array}$} & $\begin{array}{l}\text { Among the } 10 \text { instances, } 5 \text { and } 7 \text {, } \\
\text { which revolve around 'revise' } \\
\text { and 'essay', respectively, merit } \\
\text { special attention. }\end{array}$ & $\begin{array}{l}\text { Among the } 10 \text { instances, } 5 \text { and } 7 \text {, } \\
\text { which revolve around 'eexample' } \\
\text { and 'eexample', respectively, } \\
\text { merit special attention. }\end{array}$ \\
\hline & $\begin{array}{l}\text { In that study, the algorithm was } \\
\text { able to classify vowel phonemes } \\
\text { (English /i, i, E, e/ and Japanese } \\
\text { /i, i:, e, e:/) with considerable } \\
\text { accuracy }\end{array}$ & $\begin{array}{l}\text { In that study, the algorithm was } \\
\text { able to classify vowel phonemes } \\
\text { (English /eexample/ and } \\
\text { Japanese /eexample/) with } \\
\text { considerable accuracy }\end{array}$ \\
\hline & $\begin{array}{l}\text { Of the five nouns analyzed, } \\
\text { problema is the one that tends } \\
\text { to be used more frequently with a } \\
\text { terminological value in the three } \\
\text { fields. }\end{array}$ & $\begin{array}{l}\text { Of the five nouns analyzed, } \\
\text { eexample is the one that tends } \\
\text { to be used more frequently with a } \\
\text { terminological value in the three } \\
\text { fields. }\end{array}$ \\
\hline & $\begin{array}{l}\ldots \text { the word motivo is frequently } \\
\text { used in terminological } \\
\text { combinations in phrases of the } \\
\text { type exposición de motivos } \\
\text { 'presentation of motives', and } \\
\text { motivos jurídicos 'legal } \\
\text { reasons'. }\end{array}$ & $\begin{array}{l}\ldots \text { the word eexample is } \\
\text { frequently used in terminological } \\
\text { combinations in phrases of the } \\
\text { type eexample, and eexample. }\end{array}$ \\
\hline $\begin{array}{l}\text { 4. Examples } \\
\text { that cannot } \\
\text { be replaced } \\
\text { by a noun } \\
\text { No change }\end{array}$ & $\begin{array}{l}\text { Although she commented that } \\
\text { she wanted to 'find the right } \\
\text { way to express' her thoughts, it } \\
\text { is difficult to define exactly what } \\
\text { her needs are or what } \\
\text { information from the corpus } \\
\text { would help her address them. }\end{array}$ & $\begin{array}{l}\text { Although she commented that } \\
\text { she wanted to 'find the right } \\
\text { way to express' her thoughts, it } \\
\text { is difficult to define exactly what } \\
\text { her needs are or what } \\
\text { information from the corpus } \\
\text { would help her address them. }\end{array}$ \\
\hline
\end{tabular}

Examples that belonged in the register of the study were academic quotations.

These, whether formatted in-text or as blocked text, were left in the text; this is because they 
are part of the register of academic research writing and are an integral part of the text type under investigation. See \#1 in Table 3-2.

As for coding, if the language example was formatted as blocked text (\#2 in Table 32), I removed it and marked its place with <eexample>, due to the language example's nonintegral role in the sentence. If the language example served a nominal role in the sentence (\#3 in Table 3-2), it was replaced with eexample tagged as a noun, in order to both remove the text of the different register and keep the grammar of the sentence intact for analysis. A few of the language examples (\#4 in Table 3-2) were so incorporated into the sentence that removal or replacement would not have left the sentence intact and were relatively rare in the corpus; I left these in the text. By using this coding for language examples, I was able to limit the analysis to noun modification in the target register, without influence from noun modification inside language examples from other registers.

Other aspects of corpus formatting included file naming conventions and header conventions. I gave the files in this corpus each a unique filename with information about author, year, journal, and section. Headers at the beginning of each text file gave necessary information such as file name, subcorpus, names of original headings in the article, and journal.

The final step for the corpus compilation was creating the tagged version of each text. Each of the 120 texts (30 articles, 4 IMRD sections per article) was tagged for part of speech using the Biber Tagger (2009). I also ran a "fixtag" program for each text, checking each tag for present particle and past participle forms and instances of that, since accuracy of these tags was important for my analysis; for example, ed-clause postmodifiers and ingclause postmodifiers were frequently mistagged before fixtagging, with some samples of 
those tags being accurate only $38 \%$ of the time. The final tagged files enabled analysis of the corpus using concordancing software to gather counts of each type of noun modification for Analysis 1.

\subsection{Noun Modification Types}

The six types of noun modification were chosen by frequency in academic writing, as found the Longman Grammar of Spoken and Written English (Biber, Johansson, Leech, Conrad, \& Finegan, 1999, p. 589 and 606). They were the six most frequent types of noun modification. These six types included were relative clauses, ed-clause postmodifiers, ingclause postmodifiers, propositional phrases, noun premodifiers, and attributive adjectives (see Table 3-1). I excluded types that were uncommon in academic writing, such as to-clause postmodifiers (1 per 1000 words) and relative clauses with zero relativizer ( 1 per 1000 words, or about $9 \%$ of relative clauses in academic writing). Appositive noun phrases (3 per 1000 words) were also excluded because of both their need for hand-coding and their rarity.

These six types were categorized as compressed or elaborated based on Biber and Gray's (2010) study of grammatical differences in complexity between spoken conversation and academic writing. As described in the literature review, elaborated structures are clausal, while compressed structures are phrasal. See Table 3-3 for the six noun modification types and their designation as compressed or elaborated structures. 
Table 3-3

Types of Noun Modification Investigated

\begin{tabular}{|l|l|l|l|}
\hline Type & $\begin{array}{l}\text { Pre or post } \\
\text { modifier }\end{array}$ & $\begin{array}{l}\text { Compressed or } \\
\text { elaborated }\end{array}$ & $\begin{array}{l}\text { Approximate } \\
\text { frequency in } \\
\text { academic writing } \\
\text { (Biber et al. 1999), } \\
\text { per thousand words }\end{array}$ \\
\hline Relative clause & Post & Elaborated & 11 \\
\hline Ed clause & Post & Elaborated & 3 \\
\hline Ing clause & Post & Elaborated & 2.5 \\
\hline Prepositional phrase & Post & Compressed & 68 \\
\hline Noun premodifier & Pre & Compressed & 22 \\
\hline Attributive adjective & Pre & Compressed & 55 \\
\hline
\end{tabular}

\subsection{Data Analysis}

The study used two analyses to investigate the interaction of IMRD section and noun modification. The first analysis was a statistical analysis of the frequency of the noun modification types across IMRD sections. The second analysis used hand coded analysis of noun phrase structures and the patterns of noun modification within them by IMRD section to complement the analysis of noun modification frequencies from Analysis 1.

\subsubsection{Analysis 1: Comparison of Noun Modification Types}

For the first analysis, I counted the six noun modification types in each file using the concordancer MonoConc Pro (Barlow, 2002), a program which enables searches for words and grammatical tags.

The raw counts for the six noun modification types were converted to normed counts by 1000 nouns. The default base for normed counts in corpus analysis is words (Biber et al., 1999, among many others), for example 55 attributive adjectives per 1000 words (see Table 3-3). However, all of the grammatical structures under study are types of noun 
modification; in other words, they can only occur with a noun. This method of norming has precedent in Roland, Dick, and Elman (2007), who argue that for structures such as relative clauses that happen only after nouns, comparisons based on noun-counts rather than word counts give a more accurate picture. Additionally, for this corpus, using words as the base for normed counts would have distorted the data because the proportion of nouns per 1000 words is not consistent across the four IMRD sections of the corpus (see Results chapter).

The normed counts were calculated for each of the six types of noun modification for each section of each article. Because the data were not normally distributed, data analysis was done with Kruskal-Wallis tests to determine if the section differences for each of the six types of noun modification were significant. After that, post hoc pairwise comparisons were conducted for differences between particular sections using six pairwise Mann-Whitney U tests per significant noun modification type (namely, comparing I-M, I-R, I-D, M-R, M-D, and R-D). The global significance level was .05, adjusted to .0021 after Bonferroni correction for multiple test, in this case 24 tests, 6 Kruskal-Wallis tests, and 18 pairwise comparisons.

\subsubsection{Analysis 2: Structure of Noun Phrases}

For the second analysis, I sampled head nouns and analyzed the structure of the noun phrases by hand to have a representative sample of the nouns spread evenly between the four IMRD sections and 30 articles. I obtained 5 random nouns per article per section (150 per section, 600 total) using MonoConc and excluded proper nouns that were part of citations in the text, as these are very rarely modified. Following this, I identified the overall structure of each noun phrase in the sample, noting all instances of each of the six noun

modification types under study, as well as head nouns without modification. Example 3-2 
shows the labeling of noun phrase structure. In this noun phrase, the head noun techniques has two premodifiers, an attributive adjective exploratory and a premodifying noun triangulation; after the head noun is just one postmodifier, a relative clause which itself contains premodified noun phrases and an adverbial to-clause.

\section{Example 3-2}

Exploratory triangulation techniques that combine screen recordings, stimulated recalls, and corpusquery analysis to examine the behaviors and development of L2 writers in their interactions with the corpus

\begin{tabular}{|c|c|c|c|c|}
\hline $\begin{array}{c}\text { Premodifier } \\
2\end{array}$ & $\begin{array}{c}\text { Premodifier } \\
1\end{array}$ & Head noun & $\begin{array}{c}\text { Postmodifier } \\
1\end{array}$ & $\begin{array}{c}\text { Postmodifier } \\
2\end{array}$ \\
\hline exploratory & triangulation & techniques & $\begin{array}{c}\text { that } \\
\text { combine... }\end{array}$ & (none) \\
\hline ADJ & NN & $\mathbf{n n}$ & REL & 0 \\
\hline
\end{tabular}

Note: $\mathrm{ADJ}=$ attributive adjective, $\mathrm{NN}=$ noun premodifier, $\mathrm{n}=$ head noun, $\mathrm{REL}=$ relative clause, $0=$ no modifier in slot

After identifying the structure of the noun phrases, I counted instances of premodification, postmodification, and no modification and identified the most common patterns of modification, such as one attributive adjective before the head noun with one prepositional phrase postmodifier behind the head noun. I compared the rates of pre-/postand no modification by IMRD section and identified common noun modification patterns by IMRD section in order to add insights of noun modification usage and structure to the results of Analysis 1. 


\subsection{Conclusion}

In this study, I used two analyses of noun modification in a corpus of 30 empirical research articles divided by IMRD section in order to investigate whether noun modification differences reflect the functions of the four IMRD sections. I drew the analyses together by using their two perspectives on the same phenomenon. The first analysis showed the counts of the types of noun modification by section, answering RQ1 about the variation of noun modification between IMRD sections. The second analysis explored the structure of noun modification between sections; it gave more information about the complex noun phrase structures beyond simple frequency counts in order to answer RQ2. 


\section{Chapter 4. Results and Discussion}

\subsection{Introduction}

This chapter presents the results of the two analyses of the study. First I give the noun frequency differences by section that were the basis for Analysis 1, and I discuss the counts of the six noun modification types by section, while Analysis 2 describes the results of the analysis of noun phrase structures. Finally, I discuss the results of these two analyses together and what they mean for grammatical variation between the IMRD sections of research articles.

\subsection{Noun Frequency by IMRD Section}

The number of nouns per 1000 words was not consistent across the IMRD sections. As Table 4-1 describes, some sections (Introduction, Methods) had a greater density of nouns than others (Results, Discussion). This variation across sections led me to norm the raw noun modification counts to a base of 1000 nouns (see Methods section for discussion of norming decision).

\begin{tabular}{|c|c|c|c|c|}
\hline \multicolumn{5}{|c|}{$\begin{array}{l}\text { Table 4-1 } \\
\text { Nouns per } 1000 \text { words in the AppLingIMRD Corpus }\end{array}$} \\
\hline Section & Introduction & Methods & Results & Discussion \\
\hline Words & 69,630 & 42,661 & 68,334 & 46,235 \\
\hline Nouns & 23,670 & 14,275 & 20,792 & 14,830 \\
\hline $\begin{array}{l}\text { Nouns per } \\
1000 \text { words }\end{array}$ & 339.9 & 334.6 & 304.3 & 320.8 \\
\hline
\end{tabular}


This variation in noun density is due to differences between IMRD sections in the use of structures that contain nouns. Coordinated subjects or objects and types of noun modification that contain nouns (premodifying nouns, relative clauses, prepositional phrase postmodifiers, etc.) all contribute to noun density. The functions of IMRD sections may motivate the differencs in use of these noun-containing structures. The function of Introduction sections to condense arguments and previous research into the section and the function of the Results sections to clearly and explicitly describe the findings of the study may mean that these sections use more (Introductions) or fewer (Results) nouns per 1000 words.

\subsection{Analysis 1: Noun Modification Frequency by IMRD Section}

Analysis 1 set out to determine the frequency differences of six types of noun modification between IMRD sections in order to explore the connection between rhetorical function and linguistic form. Analysis 1 answered the research question:

How do the frequencies of noun modification features vary between different sections of research articles in Applied Linguistics? How do the differences of compressed and elaborated structures by section illustrate the functions of IMRD sections?

After obtaining the counts for each type, I normed them to 1000 nouns and performed a Kruskal-Wallis test with Mann-Whitney U pairwise post hoc tests with a global .05 significance level and .0021 significance level for each test, as described in the methods chapter. Note: while Analysis 1 compares the use of particular noun modification types by 
section, there are differences in the numbers of unmodified noun heads by section. These noun structure differences are discussed in Analysis 2.

\subsubsection{Results of Kruskal-Wallis and Post Hoc Tests}

The Kruskal-Wallis test compared the normed noun modification counts by section. There were statistically significant results for three of the six noun modification types: attributive adjectives, prepositional phrase postmodifiers, and noun premodifiers. The results for the other three noun modification types (relative clauses, ed-clause postmodifiers, and ing-clause postmodifiers) were not significant. The results of the Kruskal-Wallis are in Table 4-2.

\begin{tabular}{|c|c|c|c|c|c|c|}
\hline \multicolumn{7}{|c|}{$\begin{array}{l}\text { Table 4-2 } \\
\text { Kruskal-Wa }\end{array}$} \\
\hline & $\begin{array}{l}\text { Relative } \\
\text { clauses }\end{array}$ & $\begin{array}{l}\text { Attributive } \\
\text { adjectives }\end{array}$ & $\begin{array}{l}\text { Prepositional } \\
\text { phrase } \\
\text { postmodifiers }\end{array}$ & $\begin{array}{l}\text { Noun } \\
\text { premodifiers }\end{array}$ & $\begin{array}{l}\text { Ed-clause } \\
\text { postmodifiers }\end{array}$ & $\begin{array}{l}\text { Ing-clause } \\
\text { postmodifers }\end{array}$ \\
\hline $\begin{array}{l}\text { Chi- } \\
\text { Square }\end{array}$ & 1.41 & 24.72 & 18.39 & 20.58 & 7.02 & 4.23 \\
\hline df & 3 & 3 & 3 & 3 & 3 & 3 \\
\hline $\begin{array}{l}\text { Asymp. } \\
\text { Sig. }\end{array}$ & .703 & $.000 *$ & $.000 *$ & $.000 *$ & .071 & .238 \\
\hline $\begin{array}{l}\text { Groupir } \\
* \text { Statist } \\
\text { Significa }\end{array}$ & $\begin{array}{l}\text { Variable } \\
\text { ally signi } \\
\text { ice set at }\end{array}$ & $\begin{array}{l}\text { IMRD Sec } \\
\text { ficant result } \\
.0021\end{array}$ & ion & & & \\
\hline
\end{tabular}




\subsubsection{Across-section Comparisons}

\subsubsection{Attributive Adjectives}

Attributive adjectives had statistically significant differences by section. Figure 4-1 shows the means across sections, and Table 4-3 shows the results of pairwise post hoc Mann-Whitney U tests. We can see that the counts for both Introduction and Discussion are higher, while the counts for Methods and Results are lower. Discussion counts differed significantly from those of Methods and Results ( $p=.000$ for both comparisons), and the results for Introduction counts compared to Methods and Results were not quite significant after conservative Bonferroni correction ( $\mathrm{p}=.003$, which is above the .0021 significance level).

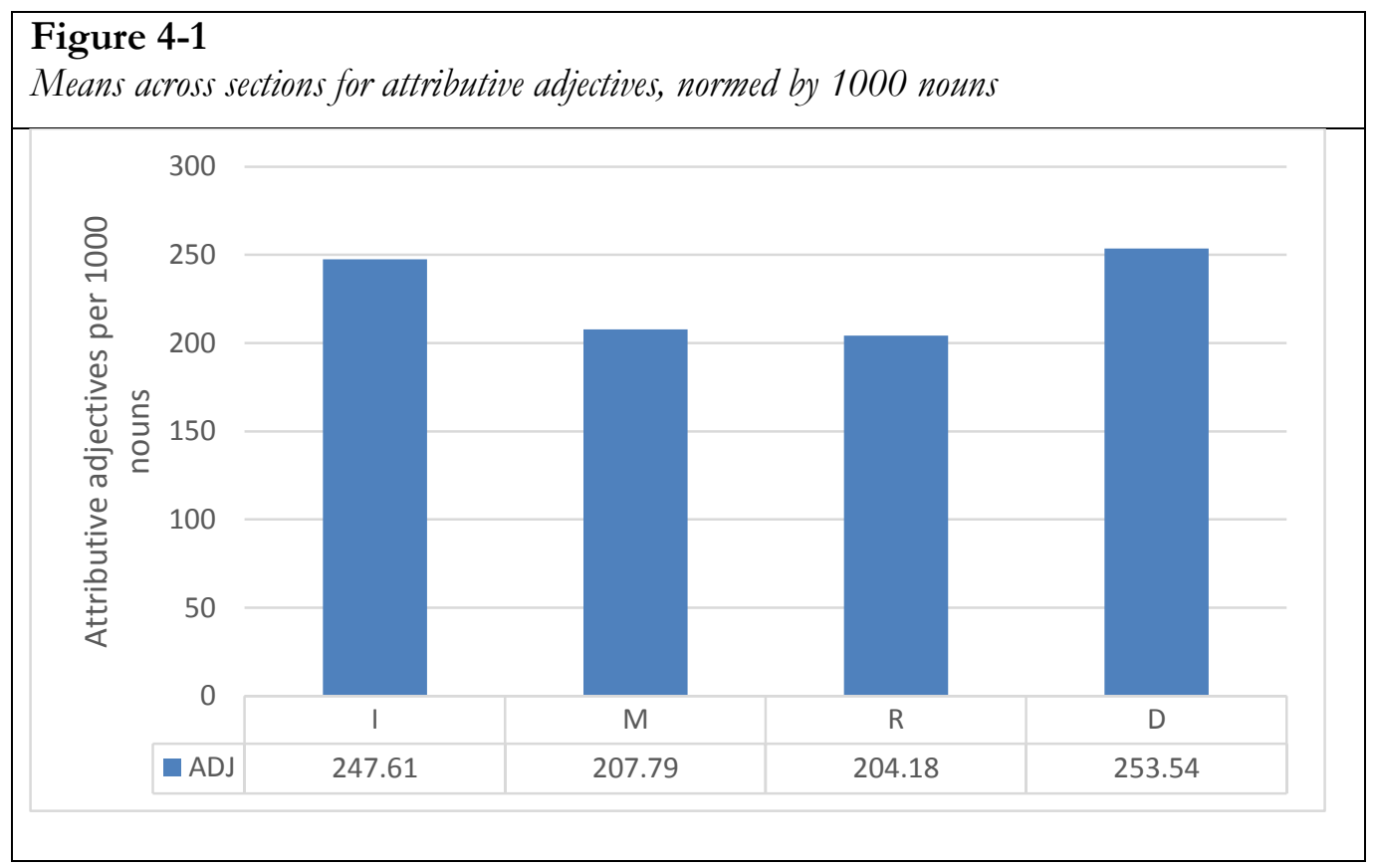




\begin{tabular}{|c|c|c|c|c|}
\hline \multicolumn{5}{|c|}{$\begin{array}{l}\text { Table 4-3 } \\
\text { Paimvise Mann-Whitney U comparisons across sections, attributive adjectives }\end{array}$} \\
\hline & Introduction & Methods & Results & Discussion \\
\hline Introduction & & $\begin{array}{l}\mathrm{U}=252.000 \\
\mathrm{Z}=-2.927 \\
\mathrm{P}=.003\end{array}$ & $\begin{array}{l}\mathrm{U}=236.000 \\
\mathrm{Z}=-3.164 \\
\mathrm{p}=\mathbf{. 0 0 2} *\end{array}$ & $\begin{array}{l}\mathrm{U}=875.000 \\
\mathrm{Z}=-.591 \\
\mathrm{p}=.554\end{array}$ \\
\hline Methods & & & $\begin{array}{l}\mathrm{U}=416.000 \\
\mathrm{Z}=-.503 \\
\mathrm{P}=.615\end{array}$ & $\begin{array}{l}\mathrm{U}=196.000 \\
\mathrm{Z}=-3.755 \\
\mathrm{p}=\mathbf{. 0 0 0} *\end{array}$ \\
\hline Results & & & & $\begin{array}{l}\mathrm{U}=181.000 \\
\mathrm{Z}=-3.977 \\
\mathrm{p}=\mathbf{. 0 0 0 *}\end{array}$ \\
\hline Discussion & & & & \\
\hline & & & & \\
\hline
\end{tabular}

Across sections, the counts for attributive adjectives followed a higher-lower-lowerhigher pattern. This is consistent with the functional differences between IMRD sections, given the function of attributive adjectives to describe, classify, and specify the subject or relationship between the adjective and its head noun (Biber et al., 1999, pp. 508-9). As for sections, Introduction and Discussion sections establish an argument and describe the space that the study will occupy or the impact and applications of the study; with these functions, it makes sense to qualify the nouns with more adjectives to build arguments. In contrast, Methods and Results have a more straightforward function; they lay out the procedure and results in a clear and replicable way. Example 4-1 shows text chunks from each of the four sections with attributive adjectives bolded. As these examples illustrate, the Introduction and Discussion sections use attributive adjectives to modify abstract nouns, such as sociocultural 
lens or developmental differences. In contrast, when attributives are used in the Methods and Results examples, they describe more specific nouns, as in simulated meetings or erroneous revisions. Additionally, the nouns in Methods and Results sections often appear alone after having been introduced, as in the students after descriptions of the CEMS students and The students in question are business students, not students of English, and are attending programmes where English is their working language. Once these nouns specific to the study have been introduced, writers can use them without modification.

\section{Example 4-1}

Examples of attributive adjective use by IMRD section, with attributive adjectives bolded

\begin{tabular}{|l|l|}
\hline I & $\begin{array}{l}\text { From a sociocultural lens, language is a powerful semiotic tool that } \\
\text { serves to mediate cognitive activity. During collaborative problem- } \\
\text { solving, learners engage in knowledge-building language-mediated } \\
\text { activities, such as formulating and testing hypotheses, or offering and } \\
\text { assessing new input. These activities can be observed in their dialogue. } \\
\text { Their talk is 'an enactment of cognitive activity' (Swain and Lapkin } \\
\text { 1998: 322). This cognitive activity and the knowledge it builds } \\
\text { represent language learning in progress (Donato 1994; Swain and } \\
\text { Lapkin 1998). }\end{array}$ \\
\hline M & $\begin{array}{l}\text { The CEMS data set consists of 19 simulated negotiations/meetings. } \\
\text { The students are assigned individual roles, and one of them acts as } \\
\text { chair. The scenario thus has some features of the meeting situation, but } \\
\text { as the participants negotiate for a result on the basis of different } \\
\text { positions and not according to an agenda, the situation is closer to the } \\
\text { negotiation genre. The situation is a pass/fail one, and they are filmed } \\
\text { with two examiners present in the room. Preparation time is } 30 \text { min, } \\
\text { and the negotiation time is 11-20 min. An overview is set out in Table } \\
\text { 2. }\end{array}$ \\
\hline
\end{tabular}




\begin{tabular}{|l|l|}
\hline $\mathrm{R}$ & $\begin{array}{l}\text { The transactions reflect the learner's efforts to address the issues that } \\
\text { arose during their writing activity. Table } 1 \text { shows that there were } 212 \\
\text { transactions, suggesting that as a group the learners had encountered at } \\
\text { least this number of challenges. The learners were able to resolve some } \\
\text { issues through their transactions-as was the case with Yujun's } \\
\text { transaction described in the previous section. In some transactions, } \\
\text { however, corpus use complicated the issues, resulting in erroneous } \\
\text { revisions that led to a deterioration in writing quality; and in a total of } \\
\text { 93 instances, no evidence was found as to whether the learners had or } \\
\text { had not benefited from using the corpus. Table 1 suggests that the } \\
\text { learners benefited to differing degrees from their corpus searches. }\end{array}$ \\
\hline D & $\begin{array}{l}\text { In contrast to structured production, the seminatural production task } \\
\text { requires participants to name a plural entity with no singular prompt, } \\
\text { and thus draws attention to the plural word rather than to its internal } \\
\text { morphological components. In this task too, BPs still lag far behind } \\
\text { the SFPs-possibly reflecting differences in size between the larger } \\
\text { SFP and the smaller BP lexicons in child Arabic. However, the nature } \\
\text { of the task brings out developmental differences. The SFPs, which } \\
\text { were easy to form under structured production, need to be directly } \\
\text { retrieved here as plurals; this was found to be slightly more difficult } \\
\text { (though not significantly so) for all groups. }\end{array}$ \\
\hline
\end{tabular}

\subsubsection{Premodifying Nouns}

Noun premodifiers were also significant. Figure 4-2 and Table 4-4 show the means by section and Mann-Whitney $U$ tests between sections, respectively. In contrast to attributive adjectives, we see that this noun modification has a lower-higher-lower-higher pattern. The use of premodifying nouns in Methods sections were significantly higher than those in Introduction and Results sections. 
Figure 4-2

Means across sections for noun premodifiers, normed by 1000 nouns

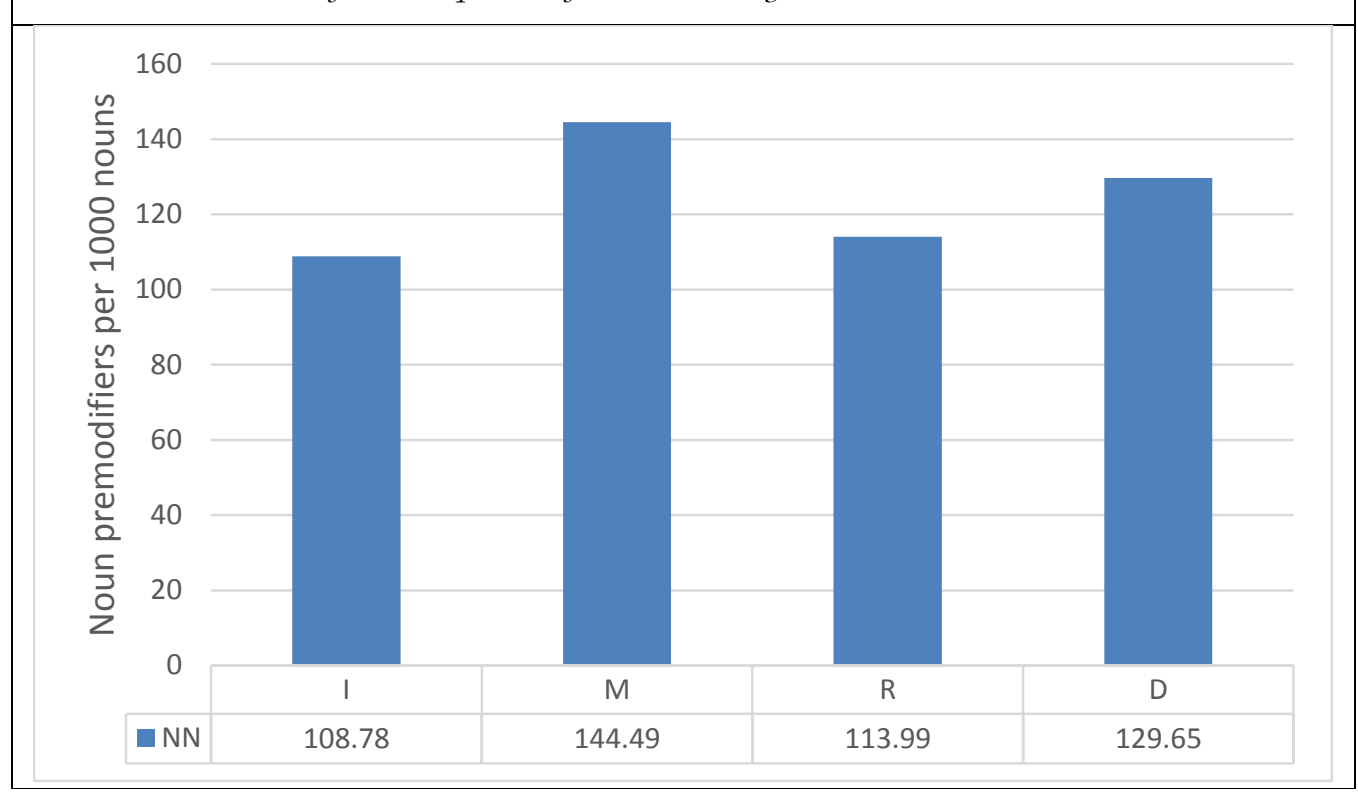

Table 4-4

Pairwise Mann-Whitney U Comparisons across Sections, Noun Premodifers

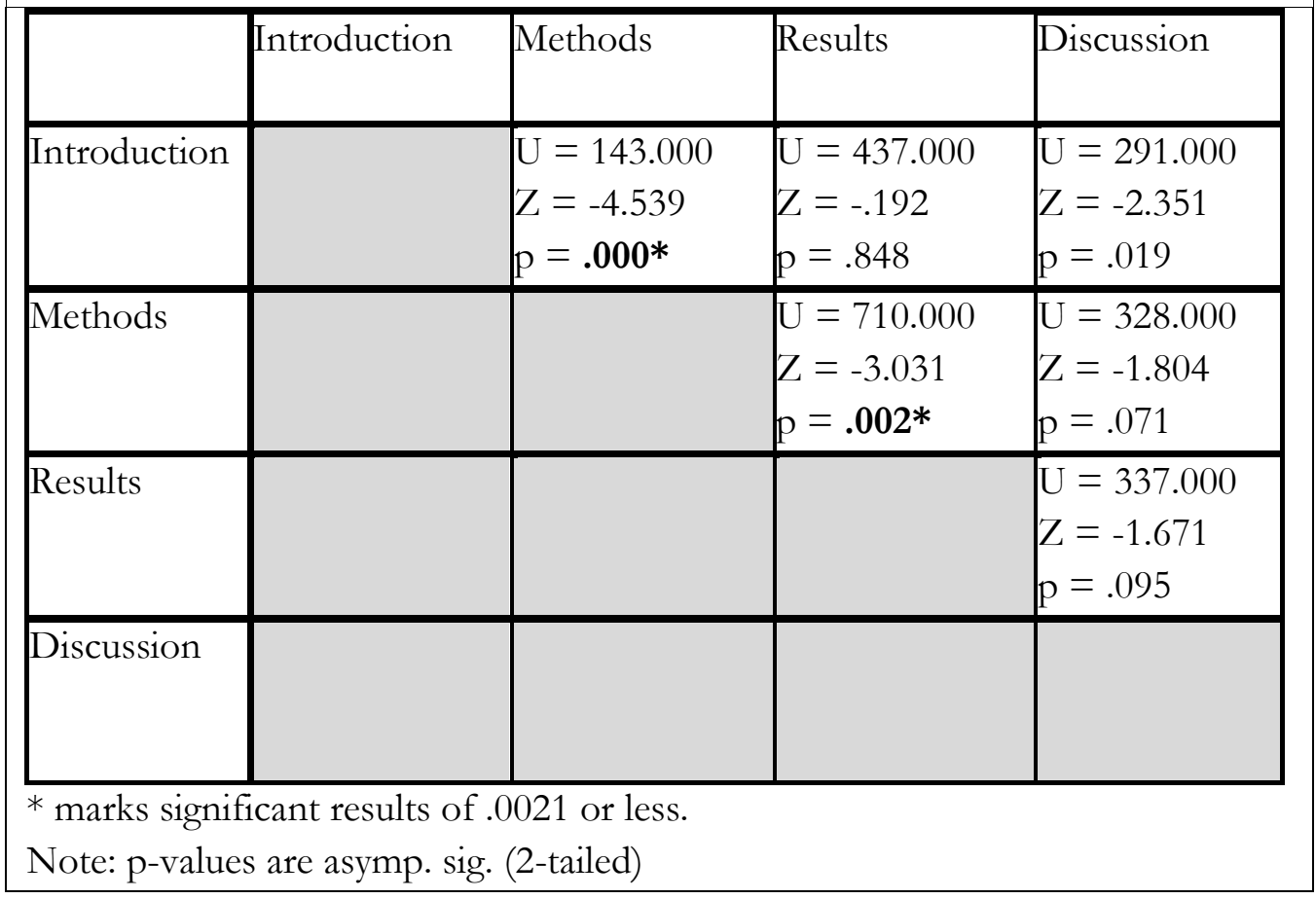


For this noun modification type, while there were some differences between the sections (as in Figure 4-2), only the differences between Introductions (lower) and Methods (higher) were significant. Before the analysis, I had expectations that Introduction and Discussion sections would have higher modification generally than Methods and Results sections, and these results were contrary to my expectations, as the highest section was Methods. The lower usage of noun premodifiers in Results sections (similar to the low usage of attributive adjectives in this section) is in line with my expectations, given the function of Results sections to clearly describe results. In Methods sections, the increased use may come from the function of noun premodifiers to indicate the type, function, or purpose of the nouns they modify, for example cluster analyses or disagreement acts, as seen in Example 4-2. Methods sections discuss research methods or approaches, which are often noun premodifer+noun sequences, as in cluster analysis, conversation analysis, corpus analysis, case study, control group, discourse analysis, speech error analysis, etc. These example noun premodifier+noun sequences show some of the functions of noun premodifiers to identify the purpose, identity, content or source (among many others) of the head noun (Biber et al., 1999, pp. 590-1). While other sections would likely mention these research methods or approaches in describing the study or making sense of its findings, it is Methods sections that spend significant time describing the research approach. 


\section{Example 4-2}

Examples of noun premodifier use by IMRD section, with noun premodifiers bolded

\begin{tabular}{|l|l|}
\hline I & \begin{tabular}{l} 
However, Biber and Conrad (2001) emphasize that considering \\
frequencies of individual linguistic features cannot reliably distinguish \\
among registers because there are too many linguistic features and \\
individual features have idiosyncratic distributions. Important \\
differences across registers are revealed when analyses are based on the \\
co-occurrence patterns of sets of linguistic features. In fact, the \\
importance of investigating linguistic co-occurrence in identifying \\
registers has been stressed by many scholars in the literature. Brown \\
and Fraser (1979), for example, mention that it is "misleading to \\
concentrate on specific, isolated [inguistic] markers without taking into \\
account systematic variations which involve the co-occurrence of sets \\
of markers" (pp. 38-39). \\
\hline $\mathrm{M}$
\end{tabular} $\begin{array}{l}\text { In Analysis 2, we consider for the first time in a mixed language the } \\
\text { possible impact of exposure to frequency differences among vowels } \\
\text { in the input on the formation of vowel categories in young children. } \\
\text { To do this we use cluster analyses of the same maternal speech } \\
\text { sample as in Analysis 1 to explore what kinds of vowel categories an } \\
\text { infant learning Gurindji Kriol might initially set up, based on certain } \\
\text { distributional data alone. On the question of what categories these are, } \\
\text { we note that distributional learning is typically presented in research } \\
\text { studies as a mechanism for learning phonemes (and in vowel studies, } \\
\text { the input data are typically limited to full vowels). }\end{array}$ \\
\hline $\mathrm{R}$ & $\begin{array}{l}\text { In line 10, S9 replies, with rising intonation and mirth (eexample), by } \\
\text { repeating S8's response. This utterance is then followed by an outburst } \\
\text { of laughter. While this utterance does not explicitly reveal whether S8's } \\
\text { response has been interpreted as impersonal, robotic, or formal, the } \\
\text { sequential placement of the repetition with rising intonation serves to } \\
\text { initiate a repair of the preceding utterance (Schegloff et al. 1977), while } \\
\text { the laughter displays the apparent humorous nature of the talk. The } \\
\text { repair initiation is particularly noteworthy, as it highlights the } \\
\text { problematic nature of eexample. S9 uses repetition and laughter as } \\
\text { resources to find fault with, and ridicule, S8's response. }\end{array}$ \\
\hline
\end{tabular}




\begin{tabular}{|l|l|}
\hline $\mathrm{D}$ & $\begin{array}{l}\text { Additionally, findings of this type of multimodal analysis can be used } \\
\text { in the design of teaching materials, always considering the possible } \\
\text { ambiguity of evaluative cues. However, it is not only the findings } \\
\text { themselves that might be useful in these realms but also the annotated } \\
\text { corpus. The multimodal transcription and annotation of the corpus } \\
\text { could also be used in the classroom to show students' instances of } \\
\text { authentic communicative situations, and to design teaching materials. }\end{array}$ \\
\hline
\end{tabular}

\subsubsection{Prepositional Phrase Postmodifiers}

Prepositional phrase postmodifiers also had significant differences. The means per section and results of the pairwise post hoc tests are shown in Figure 4-3 and Table 4-5. The rates of prepositional phrases per 1000 nouns steadily increased from Introductions to Discussions. On the other hand, this was not a very large difference and was significant only for Introduction-Results and Introduction-Discussion comparisons. The mean prepositional phrases per 1000 nouns went from about 196 in Introductions to 220 in Discussions.

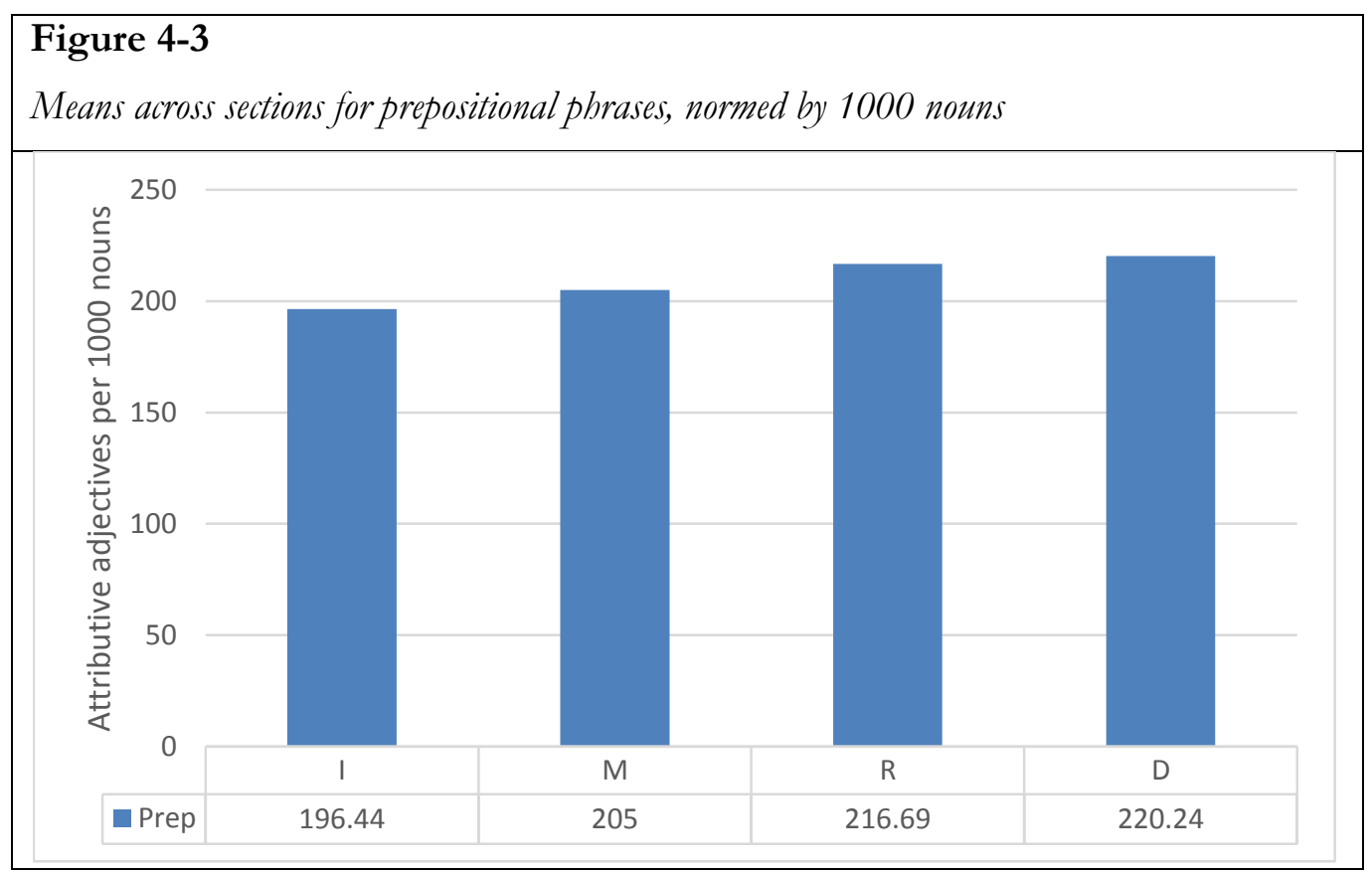




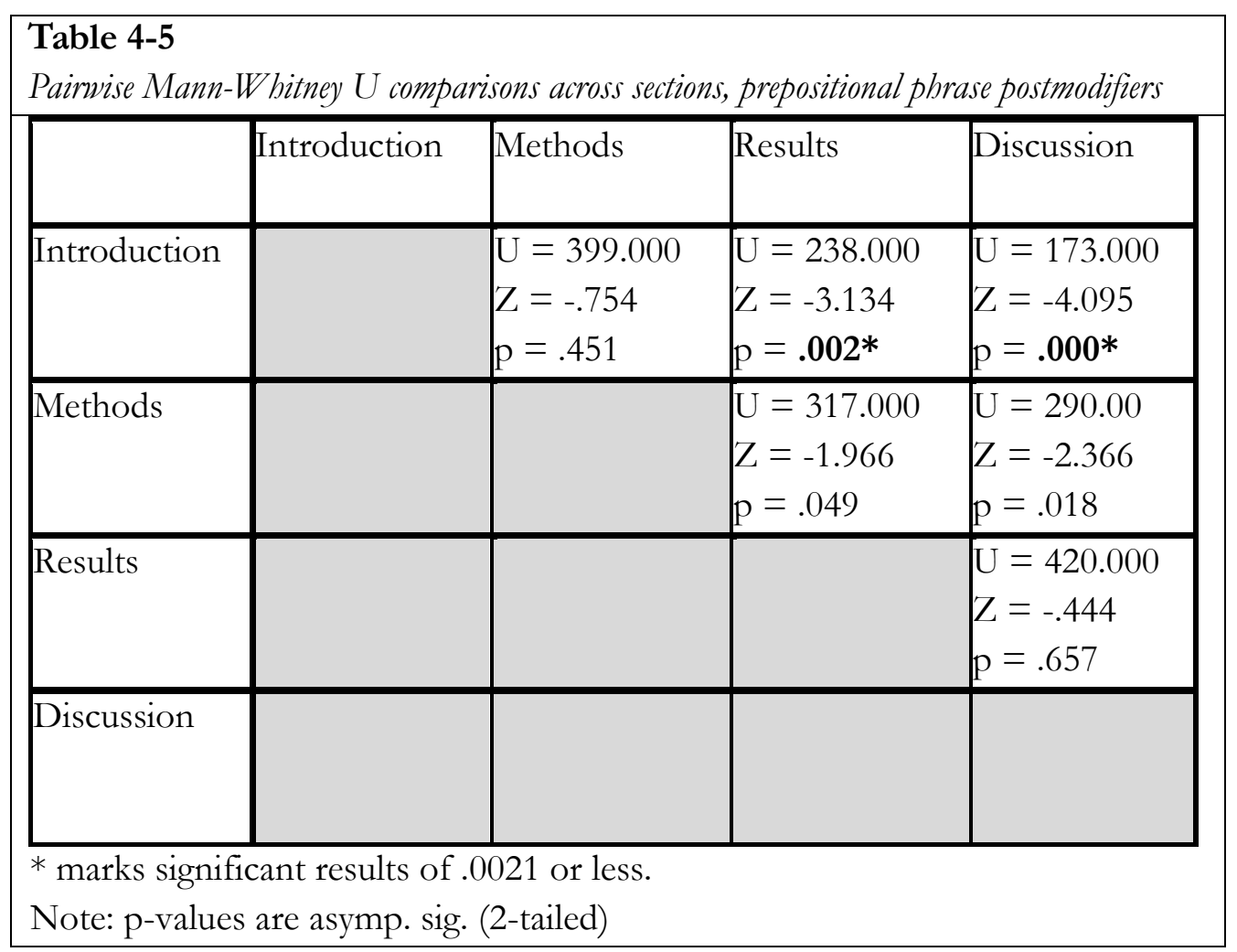

These gradually increasing rates of prepositional phrases may be related to the role of prepositional phrases as postmodifiers. Because they are postmodifiers, the choice to use prepositional phrases is connected to the principle of end weight. The principle of end weight refers to the preference of writers or speakers to place heavy (that is, long) units at the end of phrases or clauses (Biber et al., 1999, p. 898). End weight is important as a principle to explain some of the linguistic choices that writers make. Based on this principle, if we see more prepositional phrase postmodifiers from Introduction through to Discussion sections, we can guess that the noun phrases may have grown longer across the sections. Example 4-3 demonstrates some end weight related differences in examples from the first two sections (Introduction and Methods) and the last two sections (Results and Discussion). 


\section{Example 4-3}

Examples of the length of prepositional phrase postmodifiers

\begin{tabular}{|l|l|}
\hline $\begin{array}{l}\text { Introduction } \\
\text { and } \\
\text { Methods }\end{array}$ & $\begin{array}{l}\text { expressions of disagreement } \\
\text { triangulation of data } \\
\text { the structure of the lexicon } \\
\text { the level of L2 proficiency }\end{array}$ \\
\hline $\begin{array}{l}\text { Results } \\
\text { and }\end{array}$ & $\begin{array}{l}\text { a global analysis of the expression of evaluation from a } \\
\text { multimodal perspective }\end{array}$ \\
& $\begin{array}{l}\text { the frequencies and percentages of the learners' } \\
\text { incorporation of each of the three WLEs types } \\
\text { the usefulness of English for their future (instrumentality) }\end{array}$ \\
\hline
\end{tabular}

Phrases like expressions of disagreement or triangulation of data are from Introduction and Methods sections, and they contain short and simple noun modification; notably, it is possible to restructure these noun phrases so that the modification is in front of the head noun, as in disagreement expressions and triangulation of data. On the other hand, noun phrases like the diversity of the terms used by the children or a global analysis of the expression of evaluation from a multimodal perspective have very long and weighty prepositional phrase postmodifiers; these prepositional phrases would be awkward or impossible to restructure as premodifiers. While it was not within the scope of the current study to determine how often long prepositional phrases occurred in earlier or later IMRD sections, the examples illustrate a potential explanation of the increasing rates of prepositional phrase postmodifier use by invoking the principle of end weight. 


\subsubsection{Non-significant Noun Modification Types}

The non-significant noun modification types were relative clauses, ing-clause postmodifiers, and ed-clause postmodifiers, all relatively infrequent elaborated postmodifiers. The means for these noun modification types by IMRD section can be seen in Figures 4-4, 4-5, and 4-6.

These non-significant noun modification types are all postmodifiers and elaborated structures. This is interesting because the significant structures were all compressed (attributive adjective premodifiers, noun premodifiers, and prepositional phrase postmodifiers). As discussed in Biber and Gray (2010), elaborated structures are more common in conversation than academic writing. It would seem that this results in relatively flat patterns of use across IMRD sections.

Another factor relating to these three noun modification types being non-significant is their rareness compared to the significant types. The other noun modification types all occurred at least 100 times per 1000 nouns, such as attributive adjectives (about 200-250 occurrences per 1000 nouns) and premodifying nouns (about 110-145 instances per 1000 nouns). In contrast, relative clauses occurred no more than about 25 times per 1000 nouns, and ing-clauses occurred at most about 10 times per 1000 nouns. Additionally, for the three non-significant noun modification types, there was too much within-section variation in the counts of these two noun modification types for these apparent differences in mean to be significant. For example, the standard deviation for ed-clauses in Results sections is 12.5, which is large for a mean of 18.8 (66\% of the mean). For comparison, the standard deviation and mean for attributive adjectives for the same section are 47.2 and 204.2 respectively, and the standard deviation is a much smaller $23 \%$ of the mean. 


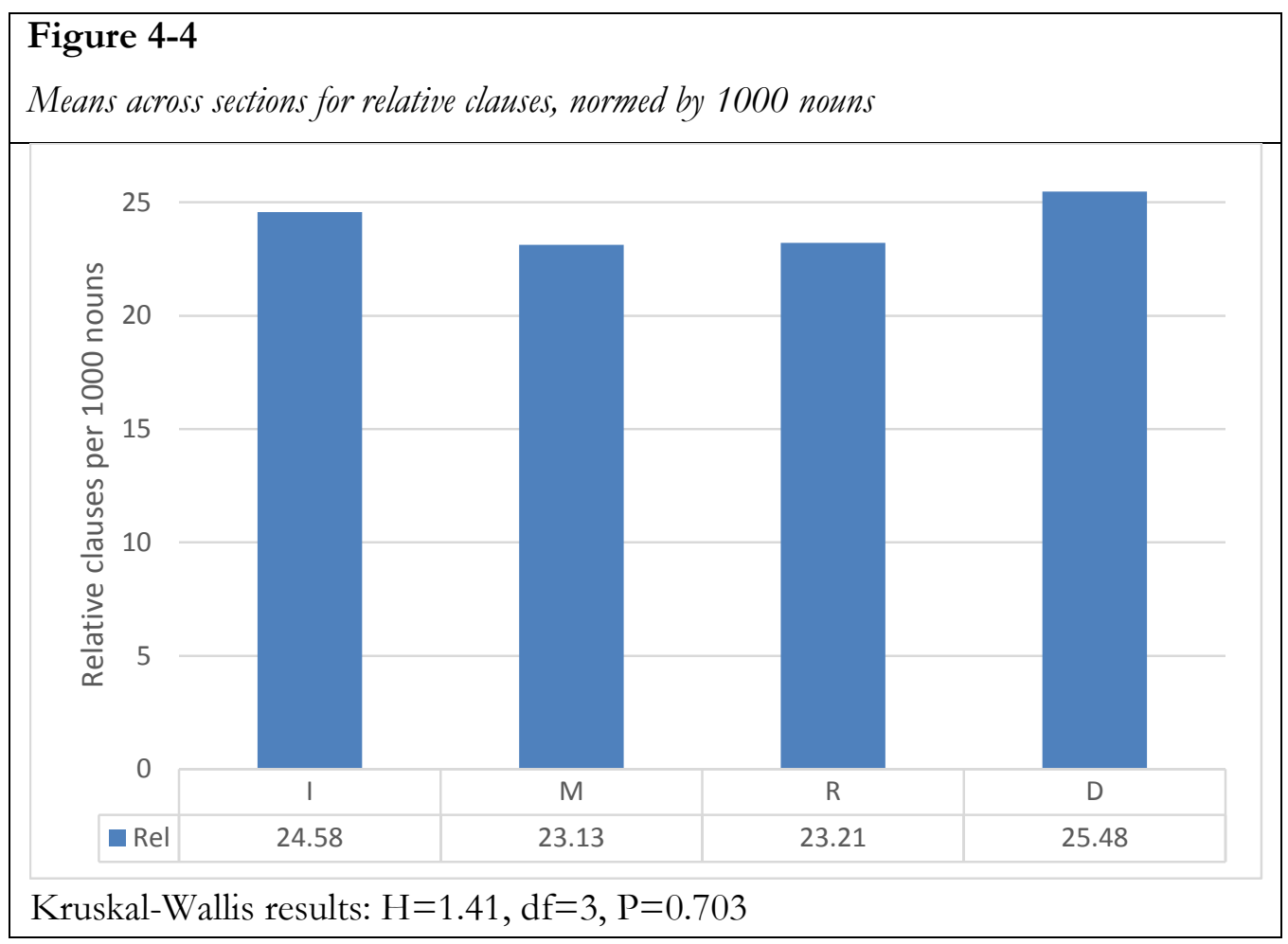

Figure 4-5

Means across sections for ing-clause postmodifers, normed by 1000 nouns

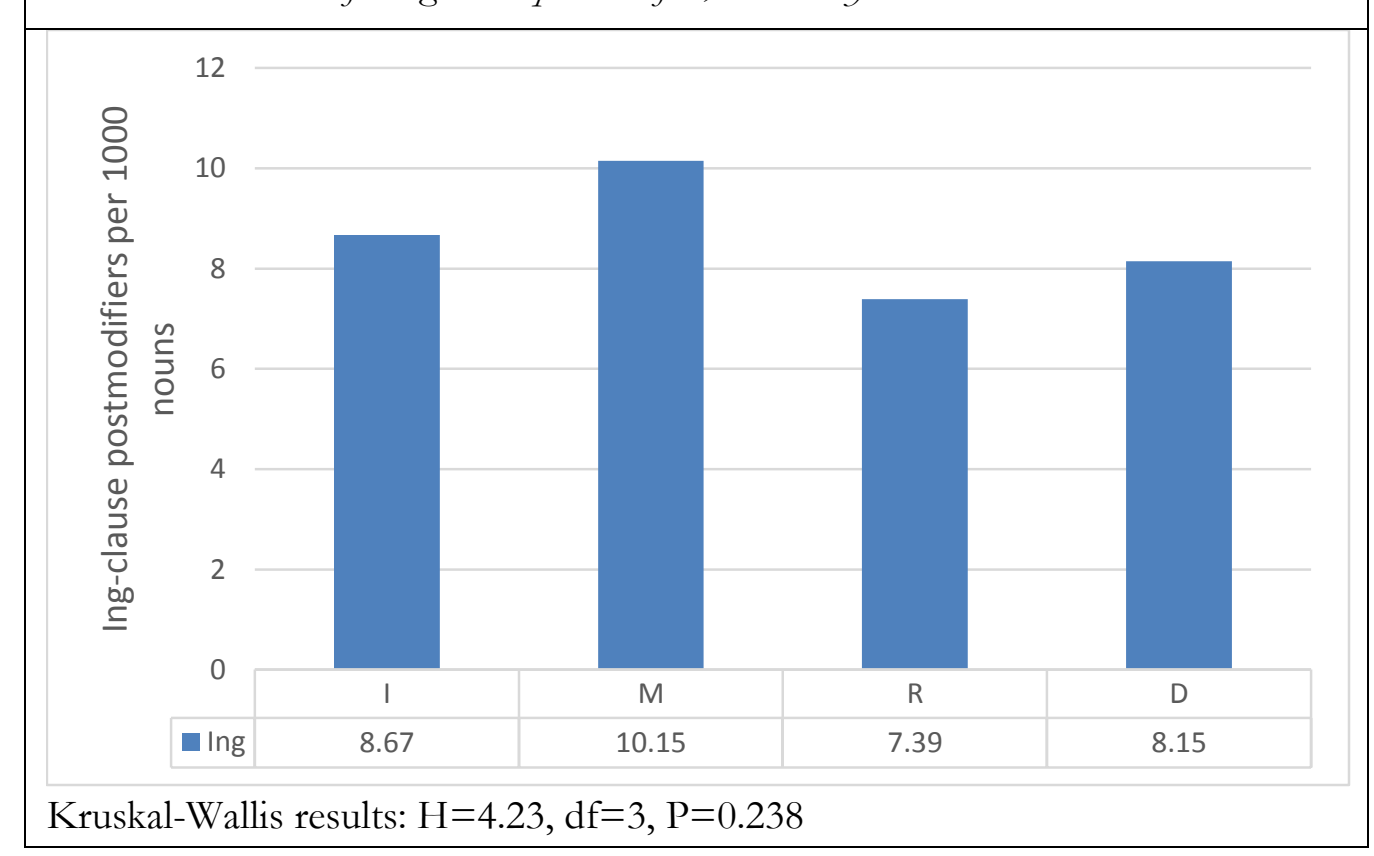




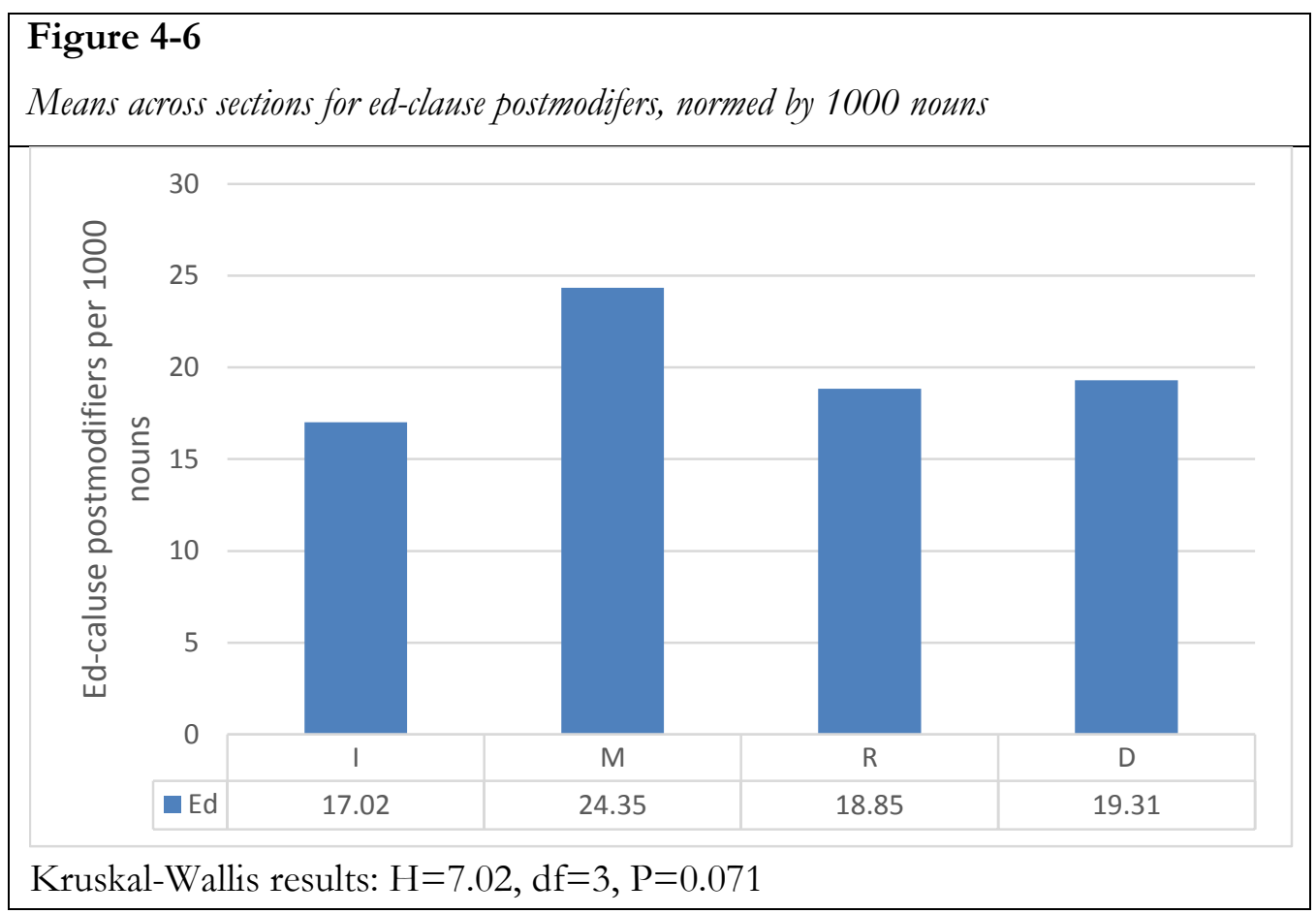

\subsection{Analysis 2: Noun Modification and the Structure of Complex Noun Phrases}

Analysis 2 set out to add a dimension to the frequency data of Analysis 1. In contrast to the larger data set of Analysis 1, Analysis 2 used an in-depth look at the structure of noun phrases across IMRD sections. This second analysis investigated the structures of complex noun phrases by section by using a sample of 600 nouns (150 nouns per section) in order to answer Research Question 2:

What are the structures of complex noun phrases in the IMRD sections of these articles? How do these structures shed light on the noun modification frequencies found in RQ1? 
To answer this research question, I counted patterns of noun modification in the 600 nouns and observed the incidence by section of lack of modification and stacked modification. The basic results for the counts of pre/post/no modification are in Figure 47. Heads nouns in Introduction sections had the lowest occurrence of no modification (36.7\%, that is, two thirds of noun heads had some sort of modification). Heads nouns in Methods had the highest rate of no modification (52\%). The counts for Results and Discussion section nouns were between the counts for Introductions and Methods in this sample, at $46 \%$ and $48 \%$ respectively.

Looking at pre- and postmodifiers and their positions in the noun phrases, we can see a few noteworthy patterns. Table 4-6 gives the noun phrases patterns in Analysis 2, from bare unmodified noun heads to noun heads with multiple instances of modification both before and after the head noun. Position 1 refers to the noun modification directly adjacent to the head noun either before or after, and Position 2 is the next noun modification position out from the head noun. Figure 4-7 gives the frequency by section for the noun phrase structures studied, excluding three patterns with consistently low frequencies of less than $2 \%$ across sections in the sample: Premod + noun + postmod + postmod $(0-2 \%)$, Premod + premod + noun + postmod $(0-1.33 \%)$, and Premod + Premod + noun + postmod + postmod $(0 \%)$. 


\begin{tabular}{|c|c|c|c|c|c|c|c|c|}
\hline \multicolumn{9}{|c|}{$\begin{array}{l}\text { Table 4-6 } \\
\text { Noun phrase structures in Analysis } 2\end{array}$} \\
\hline $\begin{array}{c}\text { Position } \\
2\end{array}$ & & $\begin{array}{c}\text { Position } \\
1\end{array}$ & & $\begin{array}{l}\text { Head } \\
\text { noun }\end{array}$ & & $\begin{array}{c}\text { Position } \\
1\end{array}$ & & $\begin{array}{c}\text { Position } \\
2\end{array}$ \\
\hline \multicolumn{9}{|c|}{ Noun } \\
\hline & & Premod & + & Noun & & & & \\
\hline \multirow[t]{5}{*}{ Premod } & + & Premod & + & Noun & & & & \\
\hline & & & & Noun & + & Postmod & & \\
\hline & & & & Noun & + & Postmod & + & Postmod \\
\hline & & Premod & + & Noun & + & Postmod & & \\
\hline & & Premod & + & Noun & + & Postmod & + & Postmod \\
\hline Premod & + & Premod & + & Noun & + & Postmod & & \\
\hline Premod & + & Premod & + & Noun & + & Postmod & + & Postmod \\
\hline
\end{tabular}

Some differences in the noun phrase structures emerge between sections. For premod+noun noun phrases, we see that a full quarter of the sample for Introduction sections had this structure, which was composed of noun + noun and adjective + noun sequences. The next most common structure for Introduction sections was noun head with a single postmodifier (noun+ postmod), making up about $17 \%$ of the sample with postmodifiers such as prepositional phrases, appositive noun phrases, relative clauses, ingclauses, and ed-clauses. These two structures were the most common (aside from bare head nouns) in all four IMRD sections, but they took up different proportions by section.

Premod+noun was most common in Introduction sections and least common in Methods sections, while Noun+postmod was most common in Results sections (about 20\%), least common in Methods sections (about 14\%), with counts in the middle for Introductions and Discussions (about 17\%). 


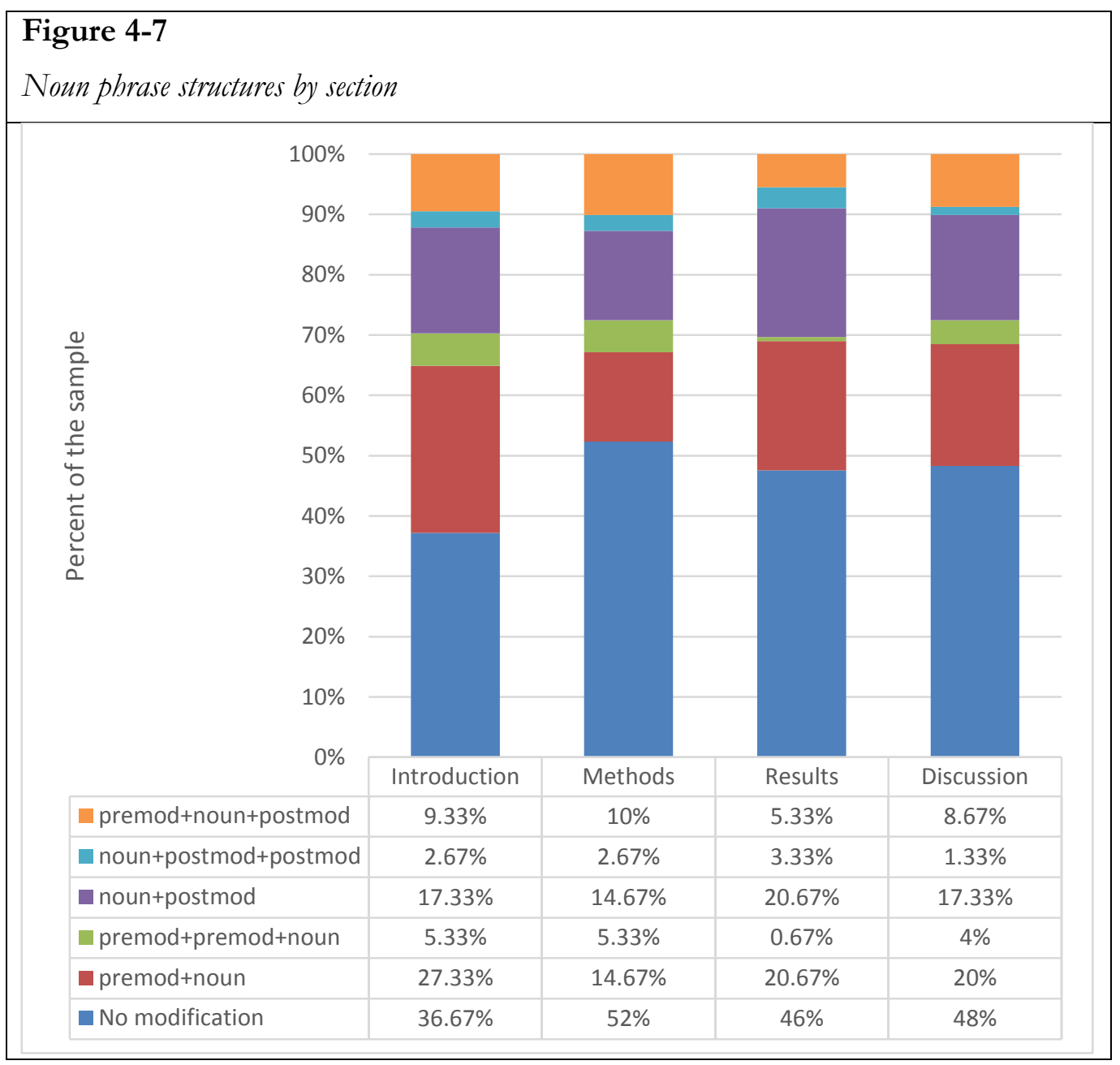

Noun phrase structures with multiple instances of noun modification were less common across the board than noun phrase structures with only one instance of modification. Some of these structures had little difference across sections, as in Noun + postmod + postmod, which ranged from about $1 \%$ to about $3 \%$ and the three noun phrase structures excluded from Figure 4-7 due to very low rates of occurrence in the sample. The other two noun phrase structures did have variation between sections. Both Premod + noun + postmod and Premod + premod + noun were approximately equally common in Introductions, Methods, and Discussions and notably uncommon in Results sections. 
Next, Table 4-7 lists the most common noun modification patterns by section, with noun modification types instead of general noun phrase structures. The table lists only noun modification patterns that occurred in at least $5 \%$ of the sample for each section. Across sections, the same patterns repeat, and the most frequent patterns for all four sections included attributive adjective alone (ADJ-noun-0), noun premodifier alone (NN-noun-0), and prepositional phrase postmodifier alone (0-noun-PP). This is unsurprising, given that these patterns all involve common noun modifiers, and none of the rarer modifiers (appositive noun phrase postmodifiers, relative clauses, ed-clause postmodifiers, and ingclause postmodifiers) appeared in the list of the commonly repeating patterns, although these noun modification types all appeared in the samples of the analyzed noun phrases. One of the patterns, attributive adjective with prepositional phrase postmodifier (ADJ-nounPP), occurred in only three of the four sections (IM_D, not in R). It was the only common pattern in the sample that contained two instances of modification. Despite the common patterns repeating through most or all of the sections, there were differences; the same top patterns repeated the most in Introduction sections, with the top patterns in that section accounting for $46 \%$ of the total sample of Introduction noun phrases and $73 \%$ of modified noun phrases. In contrast, for Methods sections, the top patterns comprise $33 \%$ of the sample and 68\% of modified noun phrases in the sample. For Results and Discussions, the numbers for each are almost the same: around $35 \%$ of the sample and $65 \%$ of modified noun phrases. In other words, Introduction sections are more homogenous, as the same four most common patterns constitute a greater proportion of noun phrases compared to the other sections. For those other sections, the less common noun modification patterns took up a greater proportion of the sampled noun phrases in those sections. 
None of the common patterns had any modification in position 2 before or after the head noun. The lack of patterns with modifiers in position 2 before or after is consistent with the results from figure 4-7.

\begin{tabular}{|c|c|c|c|c|}
\hline \multicolumn{5}{|c|}{$\begin{array}{l}\text { Table 4-7 } \\
\text { Common Patterns of Noun Modification by Section }\end{array}$} \\
\hline Pattern & I & $\mathbf{M}$ & $\mathbf{R}$ & D \\
\hline $\begin{array}{l}\text { No modification } \\
0 \text {-noun- } 0\end{array}$ & $37.3 \%$ & $52 \%$ & $46 \%$ & $48 \%$ \\
\hline $\begin{array}{l}\text { Attributive adjective only } \\
\text { ADJ -noun-0 }\end{array}$ & $15.3 \%$ & $8 \%$ & $10.7 \%$ & $12 \%$ \\
\hline $\begin{array}{l}\text { Noun premodifier only } \\
\text { NN-noun- } 0\end{array}$ & $12 \%$ & $6.7 \%$ & $10 \%$ & $7.3 \%$ \\
\hline $\begin{array}{l}\text { Prepositional phrase only } \\
\text { 0-noun-PP }\end{array}$ & $12 \%$ & $9.3 \%$ & $14.7 \%$ & $9.3 \%$ \\
\hline $\begin{array}{l}\text { Attributive adjective and } \\
\text { prepositional phrase } \\
\text { ADJ -noun-PP } \\
\end{array}$ & $6.7 \%$ & $8.7 \%$ & - & $5.3 \%$ \\
\hline
\end{tabular}

These results showed relatively little horizontal stacking in the noun phrases, that is, modification rarely spread out to position 2 and never further than position 2 . Based on my experiences encountering long and highly modified noun phrases, both through my reading and my tutoring, I had expected to find greater horizontal spread before and after the noun phrases. On the other hand, many of the noun phrases had vertical structures, namely, noun modification within modification. For example, even in the somewhat short noun phrase generalizations made in the field of ELF interaction, there is vertical stacking, diagrammed in Figure 4-8. 


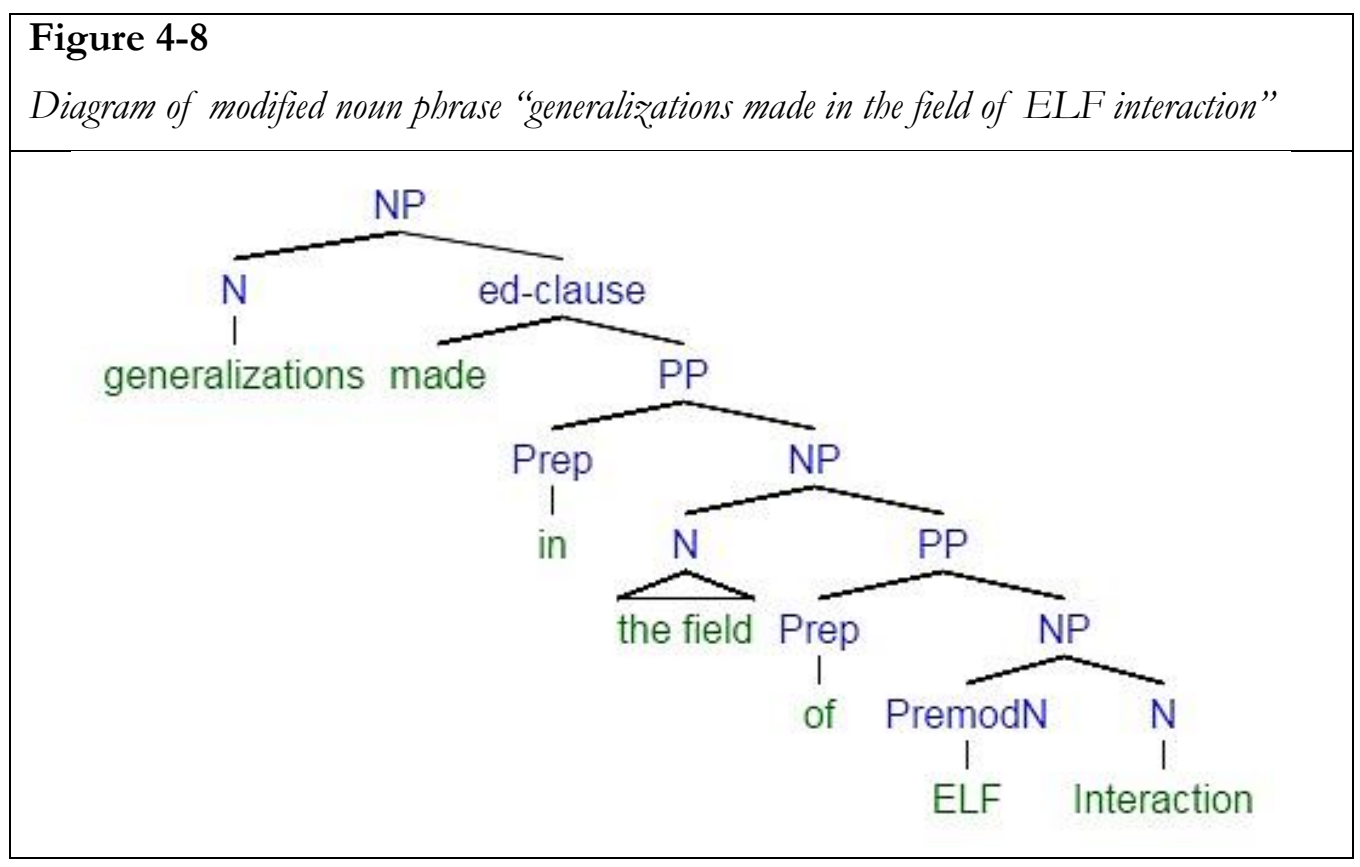

The top-level head noun, generalizations, has only an ed-clause postmodifier. This ed-clause contains the noun field, postmodified by a prepositional phrase whose object interaction is further modified by the noun premodifier ELF. A longer noun phrase from the sample from Analysis 2 with more vertical stacking of modification is even more unwieldy: Thai language that is spoken mainly in 19 provinces throughout Northeast Thailand, an area of the country that experiences an average $13.05 \%$ poverty rate... . Figure 4-9 shows the structure of this example. These examples, along with the many other instances of vertical stacking in the sample of nouns, hint at the difficulty that new readers may have parsing such complex noun phrases.

\subsection{Conclusion}

This chapter described the results of the two analyses. It found differences both in the frequencies of noun modification types across sections as well as in the noun phrase structures and patterns across sections. The next chapter will further interpret the results and consider the role of compression and elaboration in IMRD sections. 


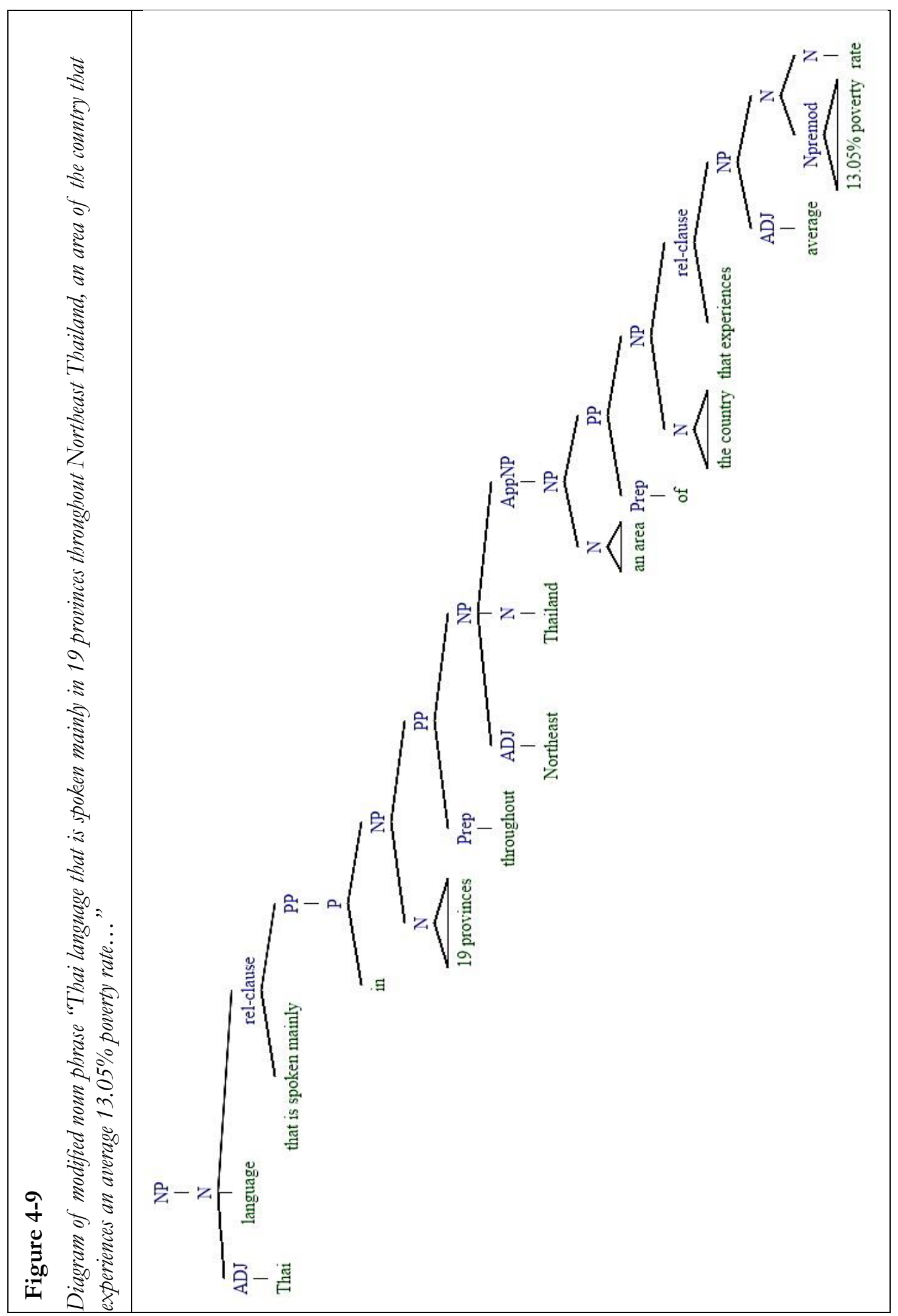




\section{Chapter 5. Conclusion}

\subsection{Introduction}

This chapter concludes the study by summarizing the main findings and then exploring the implications and areas for future study. I reflect on previous research concerning register analysis and research articles and consider what the current study adds to the field. I also discuss the potential impact of this research for students and educators in the field of applied linguistics.

\subsection{Overview and Main Findings}

This study set out to explore noun modification as it is used in the IMRD sections of research articles. Because previous research had found noun modification to be common and complex in academic writing generally and because research articles are a highly valued kind of academic writing, it is useful to have a description of how noun modification functions within research articles specifically. The study aimed to achieve this with two research questions:

RQ1 How do the frequencies of noun modification features vary between the IMRD sections of research articles in Applied Linguistics? How do the differences of compressed and elaborated structures by section illustrate the functions of IMRD sections?

RQ2 What are the structures of complex noun phrases in the IMRD sections of these articles? What are the common noun modification patterns in these 
complex noun phrases? How do these structures shed light on the noun modification frequencies found in RQ1?

\subsubsection{Research Question 1: Frequency Variations of Noun Modification by IMRD}

\section{Section}

Analysis 1 answered the first research question, which asked about frequency variation of noun modification types by IMRD section. For relative clauses, ing-clause postmodifiers and ed-cause postmodifiers, there was no significant difference between sections. The other noun modification types - attributive adjectives, noun premodifiers, and prepositional phrases - did vary significantly by section.

For between-sections comparisons of the three compressed noun modification types, Discussion sections had high counts for attributive adjectives and prepositional phrase postmodifiers, with moderately high (but not significant) use of noun premodifiers. Notably, the only noun modification type with high counts was attributive adjectives (the most frequent type of noun modification).

\subsubsection{Compressed and Elaborated Structures}

Considering the results in terms of the groups of compressed and elaborated structures, we can see that the compressed noun modification types were the only significant results, while the elaborated noun modification types all had no significant differences.

My findings are interesting in light of the use and function of compressed and elaborated structures, as described by Biber and Gray (2010). The structures associated with 
conversation (elaborated structures) did not vary significantly by section. On the other hand, compressed structures, which had been found to occur more in academic writing than in conversation, did vary by section. These differences did not, however, vary in the same way across sections for each of the three significant compressed noun modification types. In other words, no section had consistently high or low use of all three compressed noun modification types, as Table 5-1 illustrates. Introduction sections had comparatively high use of attributive adjectives with comparatively low use of noun premodifiers; Methods sections had comparatively low use of attributive adjectives and prepositional phrases with comparatively high uses of noun premodifiers. Results sections were comparatively low for attributive adjectives and noun premodifiers with comparatively moderate uses of prepositional phrases. Discussion sections had higher uses for both attributive adjectives and prepositional phrases, with no significant difference for noun premodifiers compared to other sections.

\begin{tabular}{|l|l|l|l|}
\hline \multicolumn{4}{|l|}{$\begin{array}{l}\text { Table 5-1 } \\
\text { High/Low Use of Significant Noun Modification Types by Section }\end{array}$} \\
\hline & $\begin{array}{l}\text { Attributive } \\
\text { adjective }\end{array}$ & $\begin{array}{l}\text { Premodifying } \\
\text { noun }\end{array}$ & $\begin{array}{l}\text { Prepositional } \\
\text { phrase }\end{array}$ \\
\hline Introduction & High & Low & Low \\
\hline Methods & Low & High & -- \\
\hline Results & Low & Low & High \\
\hline Discussion & High & -- & High \\
\hline
\end{tabular}

What does this tell us about the interaction of section functions and compressed/elaborated structures? Elaborated structures are grammatically explicit and speechlike, while compressed structures served to produce denser text, as in academic 
writing. That IMRD sections were effectively the same for elaborated structures emphasizes the distinction research articles have from conversation. None of the sections were more or less like conversation in terms of elaborated structures. The counts for elaborated structures were lower across all sections compared to compressed structures. For compressed structures, only Discussion sessions stand out as having consistently different uses of the three significant compressed noun modification types, while the other sections varied in their compressed counts. It is possible that this is due to the sequence of IMRD sections, which always occurred in I-M-R-D order in the corpus. It is possible for a head noun to have different modifiers with similar meaning by manipulating the noun modifiers, such as frequency differences into differences involving frequency. The value of grammatical explicitness to spell out the relationships between a head noun and its modifier may become less important over subsequent uses of a head noun with its modifier, potentially explaining the higher use of prepositional phrases and premodifying nouns in Discussion sections and lower use of those noun modification types in Introduction sections.

\subsubsection{Research Question 2: Complex Noun Phrase Structure and Patterns of Noun Modification}

As for the patterns in noun phrase structure, there was much less variation in terms of repeating noun modification patterns and instances of pre-/postmodification than the significant differences of Analysis 1 would suggest. Additionally, Analysis 2 was important in illustrating the simple structure of noun modification at the top level of noun phrases, a finding that was not possible with the analysis of the frequency of noun modification types in Analysis 1. 
While the common patterns of the IMRD sections had some differences (namely the greater homogeneity of patterns in Introduction sections compared to other sections), the overall common patterns were the same. The instances of pre-/post-/ no modification also showed Introduction sections to be different than the other sections. Introduction sections had much fewer non-modified noun phrases in the sample as well as much more premodification in position 1 . This may be related at least partly to high counts of attributive adjectives in this section, although this cannot explain the entire difference, as Discussion section also had high attributive adjective counts without its count for premodifier in position 1 going as high above that of Methods and Results sections.

In contrast to previous descriptions of academic writing or research articles as grammatically uniform text types, this research illustrates that even the rate of a head noun having modification varies between IMRD sections. This variation between IMRD sections is related to their functions. For instance, while Introduction sections must compactly make a verbal argument to lead a reader through to the research gap, Methods sections instead aim for credibility and replicability of the study. We see these functions play out in the high amount of modification in Introduction sections compared to Methods section (two thirds of noun heads having some sort of modification in Introductions, compared to just under half in Methods sections).

\subsection{Applications and Implications}

My research adds a new perspective to the well-established field of corpus linguistics. By combining a genre analysis view of IMRD sections and a register analysis view on noun 
modification, this study has given new insight into the use of noun modification within empirical research article sections. The applications for this research relate to graduate students in the field of language education and applied linguistics as they learn to read and write in a new genre.

The target group to benefit from the study is graduate students in the field of Applied Linguistics, or a closely related field, such as TESOL. These students are all proficient English users; they are speakers of English as a first or additional language. The students are learning to produce research writing in their field through reading original research and writing research projects as a part of their graduate coursework. They likely will soon be writing a thesis, dissertation, or empirical research writing paper. Additionally, these students have access to the guidance of experienced practitioners in this field, such as professors and advisors, who can give feedback on research writing. The needs of these students center upon the consumption and, ultimately, the creation of research. As they are likely already familiar with writing undergraduate academic work, such as summary and response papers and persuasive essays, they need to learn the characteristics of research writing specifically rather than academic writing more generally. Lexically, they probably have a good command of academic word choice; grammatically, they probably have an ability to use the compressed noun modification features associated with academic writing in general (see Biber \& Gray, 2010). An understanding of the ways the new genre of empirical research writing uses these features would aid students in their graduate studies. This corpus study aimed to serve the needs of these students by providing a resource for researchers and instructors to investigate lexical and grammatical differences in the sections of this genre. 
An important finding of the study with applications for teaching and tutoring is that while a large number of nouns per section are modified (ranging from 63\% in Introduction sections to a low of $48 \%$ in Methods sections), the most common patterns at the top level of the noun phrase were simple ones with only one instance of modification. On the other hand, this lack of horizontal stacking of common noun phrases was often accompanied by vertical stacking of noun modification within noun modification; in other word, while the top level of the noun phrase was simple, all levels of the noun phrase together were more complicated. Teachers and tutors wanting to prepare their students to read and produce research writing would do well to expose their students to this vertical stacking once their students have a grasp of noun modification more generally. When these students begin to read real research writing, they will almost certainly encounter it. Teachers and tutors should bring this awareness into their teaching and tutoring. When a student struggles with a long noun phrase, teachers and tutors can draw attention the stacking happening inside the noun phrase and ask students to analyze the structure to get an idea for how noun phrases are structured at the top level as well as within other modification or embedding.

\subsection{Contributions to the Field}

This study has continued the trend in register analysis to use finer and finer grained registers. In this study, I used a narrow register of applied linguistics empirical research articles and narrowed that view further to four subregisters within it, the four IMRD sections. This research contributes to the finding of register analysis that communicative function has an interrelationship with linguistic form. By focusing on the modification of nouns, I was able to demonstrate that for three types of noun modification, IMRD section does make a 
difference for use. Just as previous register analysis research was able to demonstrate that wide nets of "spoken conversation" or "academic writing" are not uniform registers, this research demonstrates that the connection between form and function follows down to the level of rhetorical sections in a text type.

Another contribution to the field by this study was the use of elaboration and compression. While elaborated and compressed structures have been studied (Biber \& Gray, 2010; Biber, Gray, \& Poonpon, 2011), few studies have applied these concepts to other register comparisons. The differences found in this study for compressed and elaborated structures suggest that these concepts may have utility for other areas of register analysis.

\subsection{Limitations and Future Research}

In aiming to use a genre lens to conduct register analysis of empirical research articles, this study ran into the issue of size. Due to the intensive pre-research work of identifying rhetorical sections, the sample size was smaller than ideal for a corpus-based register analysis. Another issue that constrained the size of the sample was the processing that each file needed in order to be formatted for the corpus. Part of this formatting process was removing extraneous parts (tables, figures, abstracts, etc.), but the formatting that constrained the practicality of using a larger corpus was the replacement of language examples (as discussed in Chapter 3). The fixing of grammatical tags with FixTag was also an issue that constrained the size. These constraints meant that a larger corpus of 50 or more articles was not feasible. With a larger corpus, analysis of less common noun modification types would be possible, such as postmodifying adjectives (e.g., considerations specific to register analysis). 
Another area of future research is comparing the IMRD sections of these articles or a similar corpus using multidimensional analysis. Biber's (as described in Biber et al., 2002) five continua for multidimensional analysis compare registers using constellations of features that occur together and give insight into the characteristics that set registers apart, such as the informational/involved and overt expression of persuasion continua (see Biber et al., 2002, pp. 15-6). For Biber's five continua, how might the IMRD sections of research articles compare to each other and to other registers of academic writing? In other words, how do the functions of IMRD sections relate to their characteristics on these continua?

Another interesting area of future research is the macro-structure of other registers. My study found differences between the sections (subregisters) of one particular register. Because rhetorical sections of other text types are able to be functionally divided, it is reasonable to suppose that some grammatical or lexical differences may exist there. For example, do the rhetorical parts of lectures or classroom presentations contain noun modification differences? Alternately, what about noun modification differences among research article types that I excluded, such as meta-analyses, reviews of literature, and articles from special issues of scholarly journals? It would be interesting to also investigate the effect of research design (that is, qualitative or quantitative methods) on the variation between sections of noun modification. Because qualitative research uses verbal descriptions to analyze data, in contrast with the numerical data used in quantitative research, would there be different use of noun modification between the sections of qualitative research and quantitative research, such as higher noun modification in Methods and Results sections for qualitative articles? 


\subsection{Final Thoughts}

This study of noun modification as it occurs in the macro-structure of applied linguistics empirical research articles found several differences between the IMRD sections that composed its corpus. In so doing, it emphasized the importance of the macro-structure of research articles as functional parts of the whole text. The noun modification differences found in the study open the door to future research that explores the interplay of IMRD functions and other linguistic features important to academic writing. Additionally, the study helps to define the use of noun modification in research articles, useful knowledge for tutors and teachers needing to understand the linguistic makeup of research writing. 


\section{References}

American Psychological Association. (2010). Publication manual of the American

Psychological Association. Washington, DC: American Psychological Association.

Barlow, M. (2002). MonoConc Pro 2.0. Houston, TX: Athelstan Publications.

Biber, D. (1999). A register perspective on grammar and discourse: Variability in the form and use of English complement clauses. Discourse Studies, 1, 131-150.

Biber, D. \& Conrad, S. (2009). Register, genre, and style. New York, NY: Cambridge University Press.

Biber, D., Conrad, S., Reppen, R., Byrd, P., and Helt, M. (2002). Speaking and writing in the university: A multi-dimensional comparison. TESOL Quarterly, 36, 9-48.

Biber, D., Johansson, S., Leech, G, Conrad, S., \& Finegan, E. (1999). Longman grammar of spoken and written English. Harlow, England: Longman.

Biber, D. \& Gray, B. (2010). Challenging stereotypes about academic writing: Complexity, elaboration, explicitness. Journal of English for Academic Purposes, 9, 2-20. doi: 10.1016/j.jeap.2010.01.001

Biber, D., Gray, B., \& Poonpon, K. (2011). Should we use characteristics of conversation to measure grammatical complexity in L2 writing development? TESOL Quarterly, 45, 5-35.

Clancy, B. (2010). Building a corpus to represent a variety of language. In A. O’Keeffe \& M. McCarthy (Eds.), The Routledge handbook of corpus linguistics (pp. 80-92). Abingdon, UK: Routledge.

Conrad, S. (1996). Investigating academic texts with corpus-based techniques: An example from biology. Linguistics \& Education, 8, 299-326. 
Conrad, S. (1999). The importance of corpus-based research for language teachers. System, $27,1-18$.

Conrad, S. (2015). Register variation. In D. Biber and R. Reppen (Eds.), Cambridge bandbook of English corpus linguistics (pp. 309-29). Cambridge: Cambridge University Press.

Cortes, V. (2013). The purpose of this study is to: Connecting lexical bundles and moves in research article introductions. Journal of English for Academic Purposes, 12, 33-43. doi: 10.1016/j.jeap.2012.11.002

Cullip, P. (2000). Text Technology: The Power-Tool of Grammatical Metaphor. RELC Journal, 31, 76-104.

Day, R. A. (1979). How to Write and Publish a Scientific Paper. Philadelphia, PA: University City Science Center.

Day, R. A. \& Gastel, B. (2011). How to Write and Publish a Scientific Paper (7 $7^{\text {th }}$ ed.). Santa Barbara, CA: ABC-CLIO, LLC.

Durrant, P. \& Matthews-Aydinl1, J. (2011). A function-first approach to identifying formulaic language in academic writing. English for Specific Purposes, 30, 58-72. doi: $10.1016 /$ j.esp.2010.05.002

Freddi, M. (2005). Arguing linguistics: Corpus investigation of one functional variety of academic discourse. Journal of English for Academic Purposes, 4, 5-26.

Halliday, M. (1993). Writing science literacy and discursive power. London: Falmer Press.

Hyland, K. (2008). As can be seen: Lexical bundles and disciplinary variation. English for Specific Purposes, 27, 4-21. doi:10.1016/j.esp.2007.06.001 
Lin, L. \& Evans, S. (2012). Structural patterns in empirical research articles: A crossdisciplinary study. English for Specific Purposes, 31, 150-160.

Liu, D. (2008). Linking adverbials: an across-register corpus study and its implications. International Journal of Corpus Linguistics, 13, 491-518. doi: 10.1075/ijcl.13.4.05liu

Miller, D. (2011). ESL reading textbooks vs. university textbooks: Are we giving our students the input they may need? Journal of English for Specific Purposes, 10, 32-46.

Parkinson, J., \& Musgrave, J. (June 01, 2014). Development of noun phrase complexity in the writing of English for Academic Purposes students. Journal of English for Academic Purposes, 14, 48-59.

Öchsner, A. (2013). Introduction to Scientific Publishing Backgrounds, Concepts, Strategies. Dordrecht: Springer.

Ozturk, I. (2007). The textual organization of research article introductions in applied linguistics: Variability within a single discipline. English for Specific Purposes, 26, 25-38.

Reppen, R. (2010). Building a corpus. What are the key considerations? In A. O'Keeffe \& M. McCarthy (Eds.), The Routledge bandbook of corpus linguistics (pp. 31-37). Abingdon, UK: Routledge.

Roland, D., Dick, F., \& Elman, J. (2007). Frequency of Basic English Grammatical Structures: A Corpus Analysis. Journal of Memory and Language, 57, 348-379.

Ruiying, Y. \& Allison, D. (2004). Research articles in applied linguistics: Structures from a functional perspective. English for Specific Purposes, 23, 264-279. 
Russell, M. K. (2014). Comparison of linguistic features in the academic writing of advanced English language learner and English first language university students (Order No. 1561157). Available from Dissertations \& Theses @ Portland State University; ProQuest Dissertations \& Theses Full Text. (1561542132). Retrieved from http:/ / search.proquest.com/docview/1561542132?accountid=13265

Saiegh-Haddad, E., Hadieh, A. and Ravid, D. (2012), Acquiring Noun Plurals in Palestinian Arabic: Morphology, Familiarity, and Pattern Frequency. Language Learning, 62: 1079-1109. doi: 10.1111/j.1467-9922.2012.00727.x

Swales, J. (1990). Genre analysis: English in academic and research settings. Cambridge, England: Cambridge University Press.

Swales, J. \& Feak, C. (2004). Academic writing for graduate students: Essential tasks and skills. Ann Arbor, Michigan: University of Michigan Press.

Wahid, R. (2013). Definite article usage across varieties of English. World Englishes, 32, 2341.

Wei, Y. \& Lei, L. (2011). Lexical Bundles in the Academic Writing of Advanced Chinese EFL Learners. RELC Journal: A Journal of Language Teaching and Research in Southeast Asia, 42, 155-166. 


\section{Appendix A: IMRD Sorting Guide}

\subsection{Instructions for IMRD Sorting}

1. Use headings and subheadings to assign IMRD sections, as far as possible. See 7.2 for the list of these headings. Headings are marked in the text with $<$ heading $=$ headingname $>$. Use MS Word's search function to search for heading $=$ to find all headings. Mark sections with $=\mathrm{I}=($ or $=\mathrm{M}=,=\mathrm{R}=,=\mathrm{D}=)$ on the line before the heading you use to identify the section.

2. In cases where the section is unclear (due to unclear heading name or unusual content/function revealed by scanning), use the description in 7.3 of IMRD functions. Use the paragraph as the unit of analysis.

\subsection{IMRD Headings}

Headings that indicate Introductions:

Introduction

No heading (if first part of article)

Literature Review

Some Background

Research Questions

The Study
Headings that indicate Methods:

Methods

Methodology

The Study

Data Collection

Procedure

Headings that indicate Discussion:

Discussion

Conclusion

Implications

Pedagogical Implications

Limitations

Areas for Future Study

Future Study 
Notes:

Two headings always require looking at the function of the section they mark. The heading The Present Study (or similar form The Current Study, etc.) may be either part of the Introduction or the start of Methods. If this section contains background, justification, and/or research questions, keep it with Introduction. If it contains specific methods, put it with Methods.

The other heading that needs skimming for function is Results and Discussion. This section is usually followed by a Conclusions section. Check the end of Results and Discussion; if the function of those paragraphs fits with the function of Discussion, label it as such. On the other hand, occasionally the entire Results and Discussion section fits with Results. In this case, you will probably label Conclusion as Discussion.

\subsection{IMRD Functions}

Each IMRD section and their functions are outlined below. The descriptions and functions are drawn from Swales (1990), Day and Gastel (2011), and Cargill and O'Connor (2009).

\subsubsection{Introduction}

The I of IMRD, Introduction, is described by Swales as "Create a Research Space" (Swales, 1990, p. 140) which is itself a model and framework in which a research describes the field and background, identifies a gap in the field that deserves further investigation, and occupies this gap to justify the current research by clarifying and specifying the current study. More broadly, the Introduction situates the study by laying out previous work that relates to 
the current work. This is also the section that states (directly or indirectly) research questions and gives a roadmap for the rest of the article. (Swales, 1990, pp. 137-148; Day \& Gastel, 2011, pp 59-62; and Cargill \& O'Connor, 2009, pp. 41-54)

Functions of Introduction sections:

Makes generalizations about an area of research

Describes past findings, generally by citing and summarizing

Relates past findings to a gap in the research

Gives structure of the rest of the article

\subsubsection{Methods}

The Method section's main functions are to make the study replicatable and to increase the credibility of the study. Both of these functions are realized in the text by outlining and describing, often in detail, the participants (or texts) under study, the tools or instruments used, and the definition and operationalization of variables. Ideally, a Methods section is clear enough to give readers sufficient and sufficiently clear information to judge the reliability/credibility and generalizability/transferability of the findings. The Methods section of qualitative and quantitative studies may feature very different content, due to the differences in approach and generalizability of each. (Swales, 1990, pp. 166-170; Day \& Gastel, 2011, pp. 63-68; and Cargill \& O'Connor, 2009, pp. 35-40) 
Functions:

Describes participants and objects

Operationalizes variables

Makes research questions adequately concrete for study

Describes tools and instruments (full description for new tools, citing and partial description for more familiar tools

\subsubsection{Results}

This section presents the results of the study. It answers the question "What did we find?" In a quantitative study, the findings after statistical analysis or analysis using an instrument or ranking are given. In a qualitative study, the findings after applying the data analysis spiral (Perry, 2011) are described. (Swales, 1990, pp. 170-171; Day \& Gastel, 2011, pp. 69-71; and Cargill \& O'Connor, 2009, pp. 21-34)

Functions:

Displays data after analysis

May provide text examples for clarity

Analyzes results

\subsubsection{Discussion}

This section discusses the findings and what they mean. It incorporates the results into something meaningful by drawing on the concepts in the Introduction, including hypotheses and theory. This is the section in which the future may be mentioned, both in 
terms of future study and applications. Implications and especially pedagogical implications are discussed here. Another function of this section is to be clear with limitations of the study and analysis (which can also occur in other places, such as the Method section).

Finally, this section moves from specific (Results) back to general. (Swales, 1990, pp. 171-

174; Day \& Gastel, 2011, pp. 72-75; and Cargill \& O'Connor, 2009, pp. 55-60)

\section{Functions:}

Provides closure for the article

Interprets results in a meaningful way

Discusses the generalizability and transferability of the results

Applies the findings to specific uses 


\title{
8. Appendix B: Human Subjects Review Not Required
}

\section{龟 Portland State}

\author{
Human Subjects Research Review Committee \\ Post Office Box $751 \quad 503-725-4288$ tel \\ Portland, Oregon 97207-0751 503-725-8170 fax \\ hsrroepdx.edu
}

To: $\quad$ Susan Conrad, Jo-Anne Hutter

From: PSU Human Subjects Research Review Committee

Date: $\quad$ May 5, 2014

Re: $\quad$ HSRRC waived review of your application titled, A corpus based analysis of noun modification in empirical research articles in applied linguistics ${ }^{\mathrm{cten}}$ IRB\#143025

The Human Subjects Research Review Committee has waived further review of your proposal as we have determined that the project does not fall under the federal regulations pertaining to research with human subjects.

Regardless of this waiver, PSU faculty, staff and students are still responsible for maintaining the highest ethical standards when conducting any projects or studies on behalf of PSU.

Thank you for informing the committee, and we appreciate your timely attention to this matter. If you make changes in the proposed project, the Committee must be notified in writing as further review may be required.

If you have questions or concerns, please contact the Office of Research Integrity, (503) 725 2227, Market Center Building, $6^{\text {th }}$ floor. 